BANCA D'ITALIA

E U R O S I S T E M A

Questioni di Economia e Finanza

(Occasional Papers)

Financial innovation oversight: a policy framework

by Carlo Gola and Antonio Ilari 

13 BANCA D'ITALIA

E U ROS I S T E MA

\section{Questioni di Economia e Finanza}

(Occasional papers)

Financial innovation oversight: a policy framework

by Carlo Gola and Antonio Ilari

Number 200 - September 2013 
The series Occasional Papers presents studies and documents on issues pertaining to the institutional tasks of the Bank of Italy and the Eurosystem. The Occasional Papers appear alongside the Working Papers series which are specifically aimed at providing original contributions to economic research.

The Occasional Papers include studies conducted within the Bank of Italy, sometimes in cooperation with the Eurosystem or other institutions. The views expressed in the studies are those of the authors and do not involve the responsibility of the institutions to which they belong.

The series is available online at www.bancaditalia.it.

ISSN $1972-6627$ (print)

ISSN 1972-6643 (online)

Printed by the Printing and Publisbing Division of the Bank of Italy 


\title{
FINANCIAL INNOVATION OVERSIGHT: A POLICY FRAMEWORK
}

\author{
by Carlo Gola* and Antonio Ilari*
}

\begin{abstract}
This paper proposes a policy framework for capturing, monitoring and containing the unintended harmful effects of financial innovation. The current approach, adopted by several authorities, makes extensive use of the tools of transparency and disclosure, mainly for consumer protection. It has been increasingly recognized that this approach needs to be supplemented with more stringent organizational solutions, which mainly include corporate governance and risk management. This also comprises responsible risk culture, ethical standards, appropriate incentive structure, accountability, and internal controls, which are related more to "process innovation" than to "product innovation". In addition to retail financial products, the policy framework also deals with the harmful effects of complex and bespoke financial contracts. This paper gives some practical examples of internal governance procedures and suggests a system-wide monitoring method for structured products. It also discusses some more intrusive policy options, including product pre-approval and prohibitions.
\end{abstract}

JEL Classification: G00, G01, G 3, G18, O31.

Keywords: Financial innovation, banking supervision, oversight, financial crisis, corporate governance, behavioural economics.

\section{Contents}

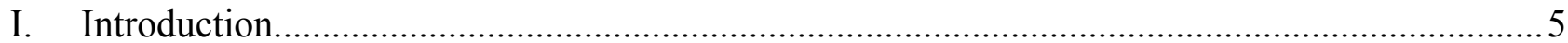

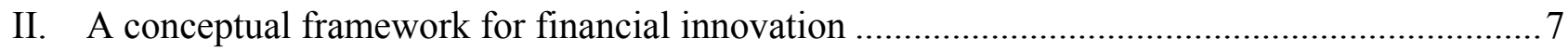

III. Financial innovation and sub-optimal outcomes: when to intervene? ................................... 13

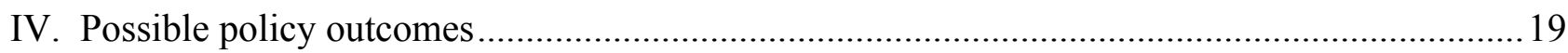

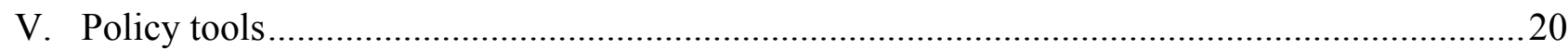

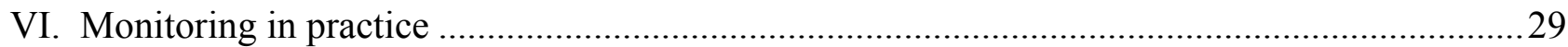

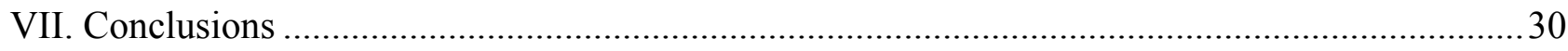

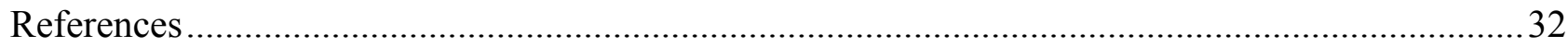

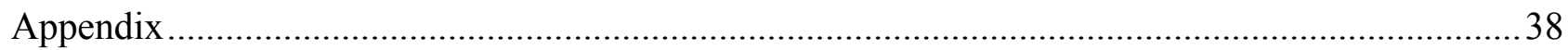

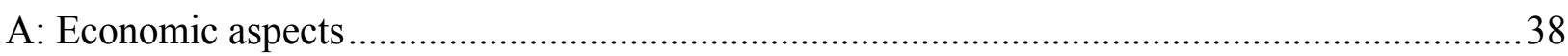

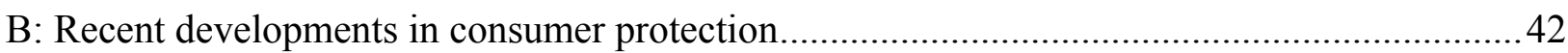

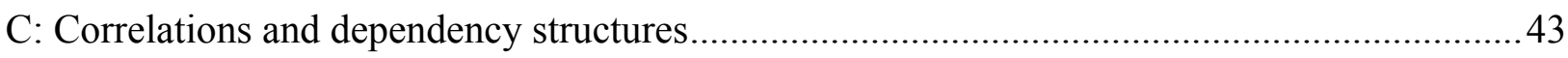

D: The EBA's Guidelines on Internal Governance .................................................................... 45

\footnotetext{
* Bank of Italy, Risk and Financial Innovation Analysis Division, Specialized Intermediaries Supervision Department.
} 



\section{Introduction ${ }^{1}$}

The current economic crisis has highlighted the importance of financial consumer protection as a tool to promote trust and confidence in financial institutions, thus supporting financial stability and economic growth. At the same time it has shown that the supervisory authorities need to consider the possibility of setting up a comprehensive system for intercepting, monitoring and containing possibly at an early stage - the unintended harmful effects of financial innovation on the financial sector and, more in general, on the economic system.

In the last decade or so, banking customers have gained broader access to increasingly complex financial products and the economic context has made consumers' financial choices more difficult, calling for increasing attention also on the part of international organizations. Although there has been a great expansion in household assets and liabilities, often individuals have not been supported by sufficient information about financial products and not adequately educated to make responsible decisions in full awareness of the associated risks. The phenomenon has often resulted in suboptimal choices and in the purchase of financial products not consistent with the individual's needs. The situation has generated a number of problems, such as household over-indebtedness, excessive risk-taking, mistrust towards financial entities, and in some cases litigation, with reputational and legal costs for banks.

Behavioural economics can help to identify a range of cognitive biases that lead consumers to make choices that are not fully rational. Such biases affect financial choices especially in situations of marked uncertainty or complexity. Policymakers should help consumers to act in their own best interests, without becoming unnecessarily intrusive.

Regulators are therefore moving in the direction of promoting more clear and effective information. Through specific public programmes, financial literacy is enhancing consumer awareness and helping individuals make better financial decisions.

On the supply side, the creation and use of increasingly complex products can lead to excessive risk-taking and negative externalities. This behaviour can be explained by various factors, such as wrong incentive structures that reward short-term profits or limited awareness of the risks associated with new, highly sophisticated financial products or contracts.

The complexity of financial products is often related to financial innovation, defined as the creation and development of new financial products or services for both consumers and producers. Financial innovation is driven by several factors, such as new forms of resource and risk allocation (risk sharing, portfolio diversification, hedging and risk management, etc.) as well as the search for temporary profits through price arbitrage, provision of liquid assets, reduction of transaction costs, and so on. It can also be encouraged by regulatory arbitrage or strategies aimed more generally at circumventing existing legislation or regulations, including tax avoidance.

The net social welfare effect of financial innovation can, therefore, be either positive or negative depending on several factors: on the one hand, a more innovative financial system is superior in the

\footnotetext{
${ }^{1}$ We are very grateful to Domenico Albamonte, Riccardo Basso, Michele Leonardo Bianchi, Diana Capone, Agostino Chiabrera, John Kiff, Andrew Laidlaw, Marcello Minenna, Luca Zeloni, and Luca Zucchelli for their very helpful comments and suggestions. The paper was prepared as a background document discussed at the EBA Task Force on Intervention Strategy - Standing Committee on Consumer Protection and Financial Innovation; it does not necessarily reflect the EBA's policy stance on this topic. The opinions expressed are those of the authors alone and do not necessarily reflect those of the Bank of Italy.
} 
sense that it helps to "complete the market", to reduce frictions and transaction costs, and to increase liquidity; on the other hand, it can be a source of negative externalities (generating systemic risks such as excessive leverage or volatility), and sub-optimal results for some classes of economic agents. Unethical behaviours can further exacerbate such negative outcomes.

The suggested framework tends to shift attention from the product to the process. Therefore, in addition to retail financial products, the policy framework also deal with the harmful effects of complex and customised, bespoke financial contracts; this includes assessing the suitability of contracts that are likely to have a material impact on the counterparty, which could be either an intermediary or entities such as nonfinancial corporations, municipalities, etc. Although simple and transparent financial products can also be a source of significant risks for the subscribers, our analysis manly focuses on the risks created by excessive complexity and opacity.

In terms of policy options, in addition to the traditional transparency, disclosure, financial literacy policies and standards of conduct for financial providers (typical tools of financial market or financial conduct regulators), it is important to consider effective internal governance and organizational arrangements, including remuneration policies and, possibly, the introduction of a New Product Committee; where satisfactory results are not achieved by these means, more intrusive measures should, in principle, be considered. Specific legislation, warnings on certain products or services, and temporary prohibitions or restrictions should also be considered.

Before proceeding with the analysis, some methodological caveats are needed. Apart from a short passage on the necessity of adopting a paternalistic approach, and of introducing an ethics statement in the list of duties of the New Product Committee, this paper does not pass any judgement on the social values of financial innovation outside the standard paradigm of utilitarianism. ${ }^{2}$ Another important caveat concerns the point of view of the paper: while we underline the need to follow a consistent and coordinated approach with financial market regulators, our point of view remains that of the banking regulator, with the ultimate goal of preserving the soundness of the banking system. ${ }^{3}$

Unlike the field of consumer protection, where several policy papers are available, there are, to our knowledge, only a few comprehensive policy papers on financial innovation that discuss the nature of the phenomenon and why and how the regulator should intervene. ${ }^{4}$

The paper is organized as follows: a conceptual framework to describe and discuss the main aspects of financial innovation (definition, functions, evolution) is provided (Section II); the identification of potential market failures and sources of risk is described (Section III), as well as policy implications (Section IV). A set of general principles and the policy tools available are considered (transparency and disclosure, financial education, internal governance, financial market technical standards, issue of "warnings" in case of "serious threat", restrictions or temporary prohibitions on

\footnotetext{
${ }^{2}$ This analysis would require us to discuss in depth the relationship between duties and the social consequences of some decisions also considering a non-utilitarian approach (see A. Sen 1991 and, for a discussion on non-utilitarianism, A. Sen and B. Williams 1982). A useful background for comparing and contrasting different ethical approaches can be found in Kutschera (1991). On ethics and finance see J.R. Boatright (ed.) (2010). For a brief overview of the ethical aspects of financial innovation see Armstrong et al. (2011). For a specific analysis on ethics, banking and the recent crisis, see P. Koslowski (2011), part III.

${ }^{3}$ For a recent discussion on complex financial products and transparency from the perspective of the financial market regulator, see Berker (2012).

${ }^{4}$ By contrast, the literature on the macroeconomic and social effects of financial innovation is extensive. For a recent contribution, see Arcand (2012). Equally extensive is the literature on financial innovation and demand for money. For a recent paper on financial innovation and the role of information, see Piazza (2010). Among the few recent papers on the regulation of financial innovation, see Lumpkin $(2009,2010)$ and World Economic Forum (2012).
} 
financial products, product pre-approval) (Section V). Finally, Section VI outlines the characteristics of a possible monitoring system. Section VII provides some concluding remarks.

\section{A conceptual framework for financial innovation}

A broad definition of financial innovation: we define financial innovation as the creation and development of new financial instruments matching the needs of consumers, producers, financial intermediaries, and governments. Innovation comprises both the enhancement of traditional financial instruments and the creation of brand new financial products or services. A financial instrument is a contractual right that has a monetary value, or represents a legally enforceable (binding) agreement between two or more parties; it can also be a physical product, specifically designed to support monetary or financial transactions.

Functions of financial innovation: the aim of financial innovation is to improve the utility of agents through various economic functions or objectives: ${ }^{5}$ 1) spatial and inter-temporal allocation of risks or financial resources (risk sharing, portfolio diversification, hedging and risk management, intermediation of resources between sectors); 2) extraction of information to support decisionmaking (pricing, rating); 3) search for temporary profits through price arbitrage both in the OTC and in organized markets; 4) provision of liquidity, safe assets and credit; 5) reduction of transaction costs (provision of medium of exchange, means of payment, services to support market trading and efficient price discovery); 6) reduction of agency costs and information asymmetries; 7) product differentiation or creation of new products, including in order to gain market power, and, 8) reaction to the normative environment (tax avoidance or evasion, accounting manipulation, regulatory arbitrage). A single innovation can simultaneously involve a bundle of such economic functions.

Policy implication 1: Financial innovation involves a number of deeply intertwined economic functions, ranging from new forms of credit intermediation to various financial instruments or contracts. Such instruments can be traded both in organized or OTC markets and in the retail and wholesale sectors. Consequently, all traditional policy objectives (stability, efficiency, transparency, market integrity, orderly market functioning, fairness, depositors' and investors' protection), being closely interconnected, need an integrated and consistent policy framework and enforcement. For these reasons, in the area of financial innovation, strict cooperation between banking and financial market regulators is particularly important.

The scope of our analysis includes the above economic functions or objectives that are performed both by banks and by non-bank financial intermediaries generating bank-like risks (called the shadow banking system). ${ }^{6}$ The shadow banking system includes entities such as broker-dealers, finance companies, asset management companies, investment funds (hedge funds, mutual funds, private equity funds, real-estate funds, money market funds, ETFs, etc.), securitization vehicles (SPVs, SIVs, etc.), and finance guarantors. It also includes activities that are a source of bank-like risks such as non-traditional repo transactions or securities lending contracts. ${ }^{7}$ The suggested framework remains valid irrespective of possible structural transformations of the banking system (Volker rule, ring-fencing rule, etc.).

\footnotetext{
${ }^{5}$ This classification is partially consistent with Tufano (2003), Lerner and Tufano (2011), Merton (1995), and Allen and Douglas (1994).

${ }^{6}$ On the definition of shadow banking, see FSB (2011a). On shadow banking and the social value of financial innovation see Turner (2012).

${ }^{7}$ This approach, recommended by the FSB to banking regulators, is also consistent with the following IOSCO principle: "The regulator should have or contribute to review the perimeter of regulation regularly" (Principle 7), IOSCO (2011a). In particular: "A regular review of the perimeter of regulation will also consider the effectiveness of existing regulations and the need to modify them or adopt new regulations in light of new market developments" (IOSCOb, p. 43).
} 
Policy implication 2: The scope of our policy action should include the financial innovation generated not only by banks but also by the shadow banking system. A pre-condition is a wide regulatory perimeter able to capture most of the shadow banking risks. ${ }^{8}$

Economic nature of financial innovation: innovation is the act of producing and developing new physical products, services or processes, among other by means of organizational changes both within the firm and through its network. This includes the design, scaling-up and distribution of new financial products. In practice, this is a three-stage process: investigating potential demand, creating the product or service, and validating the company's internal procedures (to assess the product and minimize risks, including legal, operational and reputational risks). Financial innovation normally requires a combination of advanced quantitative finance, legal engineering, and information technology.

While most financial innovation pertains to the evolution of existing financial instruments (e.g. increasingly complex forms of securitization), in some cases the innovative content is higher and more similar to a brand new product, for instance CDSs or ETFs. Therefore, as described by the standard theory of economic innovation, it is possible to distinguish between incremental innovation and radical innovation. The former is built upon existing knowledge and simple product differentiation, while the latter refers to a major technological change or the supply of previously inexistent products or services.

The interaction between market structure and $R \& D$ intensity depends on several factors, such as large sunk costs, product differentiation, economy of scale, positive network externalities, etc. ${ }^{9}$ the possibility to patent financial innovation (for instance financial algorithms) is normally limited and, therefore, the dissipation of the appropriability advantages could be high. It is reasonable to assume that the level of concentration in the most innovative segment of the market - dominated by broker-dealers, large asset management companies, and investment banks - increases the incentive to innovate. Supernormal profits for market leaders could however leave room for transitory extra profit opportunities to followers, typically small dynamic firms (such as small investment firms or hedge funds). We expect the former to be highly specialized in both radical and incremental innovation, while the latter are mainly strong in incremental or step-by-step innovation. Financial innovation can involve both physical products (for example ATMs) and processes (electronic platforms for over-the-counter markets, new financial algorithms for flash-trading, etc.).

Some products, such as ATMs or smart cards, are truly innovative at their inception, but their characteristics and market diffusion soon stabilize, reaching the phase of maturity along the product life-cycle S-shaped curve; ${ }^{10}$ other products are revitalized and mutate, creating a "jump" in the product's diffusion in the market (see Figure 1). Such mutations, which transform the characteristics of the original product, can be a source of new kinds of risk. This was the case of securitizations; initially very simple and transparent financial instruments, they were subsequently transformed into more complex and opaque structures (e.g. the CDO square).

\footnotetext{
${ }^{8}$ On the regulatory perimeter, we believe the expansion of the area under regulation should be supported by the principle that entities undertaking similar risks should be subject to equivalent prudential standards, i.e. where the activity raises shadow banking risks, the same type of rules should apply consistently across financial sectors and jurisdictions, though tempered by the proportionality criterion.

${ }_{9}^{9}$ Among the few articles on the topic, see Lerner (2006); Bhattacharyya and Nanda (2000).

${ }^{10}$ On the diffusion process of innovation, see Hall (2003).
} 


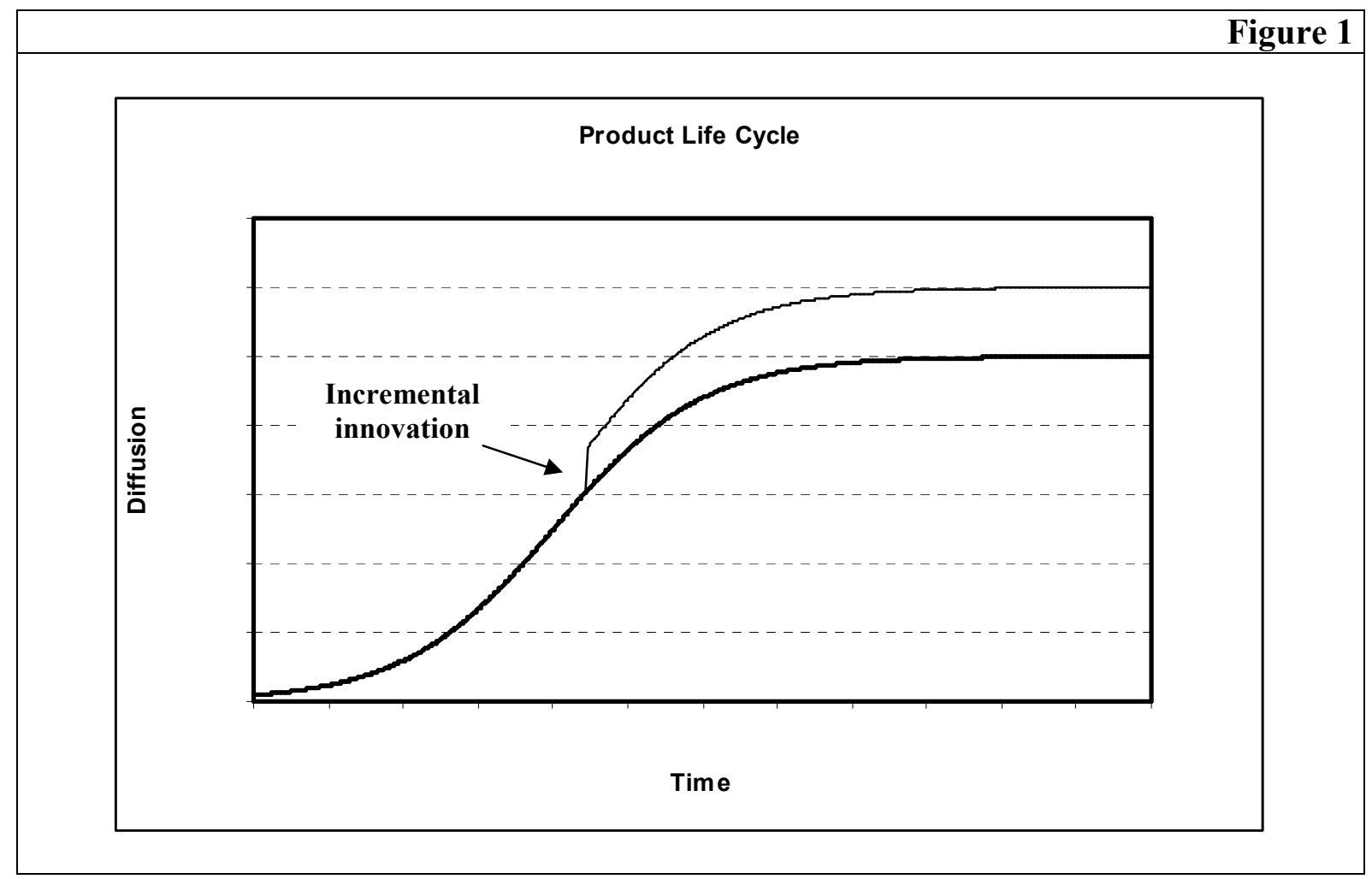

From the theoretical standpoint, recent literature underlines the importance of the evolution of a financial product's life-cycle. According to Gennaioli et al. (2012), several episodes of financial innovation share the following pattern: in some circumstances investors show a strong demand for a particular traditional financial asset; the excess of demand over supply stimulates financial intermediaries to financially engineer new securities with similar cash flows. As time passes, the new securities become increasingly complex and embed more risks. At some point, it could become apparent that the new securities are vulnerable to some unexpected risks, and in particular are not good substitutes for the traditional securities. The result is that both investors and intermediaries are surprised by the news, and investors sell these false substitutes, moving back to the traditional securities with the cash flows they seek.

False substitutes and financial instability: Gennaioli et al. (2012) underscore that, as investors head for safety, financial institutions are left holding the supply of new securities (or worse, have to dump them in a fire sale because they are leveraged). The prices of traditional securities rise while those of the new ones fall sharply. False substitutes, therefore, lead to financial instability and may reduce welfare, even without the effects of excessive leverage: "If this perspective is correct, it suggests that recent policy proposals, while desirable in terms of their intent to control leverage and fire sales, do not go far enough. It is not just the leverage, but the scale of financial innovation and of creation of new claims itself that might require regulatory attention". They therefore suggest that "it might be better to help investors form more realistic expectations by mandating that these funds be marked to market" (see Gennaioli et al., p. 466). ${ }^{11}$

Policy implication 3: Monitoring financial innovation implies an effort to intercept new phenomena and their evolution at an early stage. To this end, the standard analysis based on public and supervisory information is necessary but not sufficient; it has to be complemented with targeted market intelligence and interviews with intermediaries, designed to give a clear understanding not only of the new products, but also of their qualitative evolution.

\footnotetext{
${ }^{11}$ Therefore, the authors consider among the policy options also product intervention, where required (see Section V).
} 


\section{Box 1 - Financial engineering and structured products}

Traditional financial instruments are negotiable financial claims such as standard debt securities, shares, and investment fund shares or units. Loans, deposits, trade credits and insurance technical provisions are examples of traditional non-negotiable financial instruments. Typical innovative financial instruments are financial derivatives, which are not securities even if they are negotiable financial instruments. They are linked to specific financial or non-financial assets, or indices through which financial risks can be traded in their own right on financial markets. A combination of traditional financial instruments and derivatives is a source of incremental financial innovation. All combinations of financial instruments can be seen as bundles of cash flows. They are designed so that market participants can trade those cash flows having different characteristics and different risks (either on regulated exchanges or on OTC markets).

Several institutions and authors have tried to develop a taxonomy and list of financial instruments. ${ }^{12}$ While very useful for defining and classifying various products, all these effort are unsuitable by definition to capture new instruments and their evolving nature.

The aim of financial engineering is to understand how to price and hedge an instrument, and assess the risks associated with it. In order to do so, it is necessary to consider the cash flows generated by an instrument during the lifetime of its contract. Then, using other (hopefully) simpler liquid instruments, these cash flows are replicated creating a new synthetic financial product or "contractual equation". ${ }^{13}$ The evolution of structured products (defined as any security with a derivative component) is therefore part of financial innovation and should be monitored systematically (see Section VI). Complex structured products usually have the following features: (i) leverage; (ii) illiquidity; (iii) the potential for losses in excess of the initial investment; (iv) lack of price transparency; and (v) non-linear payouts.

Financial innovation is often driven by normative and regulatory factors. For example, the development of constant-NAV money market funds (MMFs) in the US in the early "70s was a reaction to Regulation Q. ${ }^{14}$ Another example is the development of Special Purposes Vehicles (SPVs) to reduce bank capital requirements in the '80s (although securitizations have many other economic functions). What is interesting in MMFs and SPVs is their evolution: both were introduced decades ago, but only recently during the financial crisis did they become a source of major systemic risks. For example, constant-NAV money market funds are intrinsically unstable and prone to runs as they are forms of quasi-deposit without the fully-fledged regulation of deposit takers (capital and liquidity buffers, deposit insurance, central banking facilities). However, for years they did not experience major systemic problems: it was only when they began to be part of a more complex intermediation chain with strong interconnections with the banking sector and the repo market (as well as with other shadow banking entities) that they emerged as a source of systemic risk. ${ }^{15}$ The lesson here is that the context matters and we should not limit our analysis to the financial instruments, but expand it to understanding the economic and legal environment as well. Moreover, the case of MMFs shows that abolishing Regulation Q did not reverse the market trend. Such inertia should stimulate the regulator to seek the deeper reason for this persistence, which could be rooted in some new form of regulatory arbitrage. Similarly, a specific macroeconomic condition (for instance prolonged periods of very low interest rates due to

\footnotetext{
${ }^{12}$ See BIS-ECB-IMF (2009); Finnerty (1993); Walmsley (1988); Bank for International Settlements (1986).

${ }^{13}$ Neftci (2004).

${ }^{14}$ From the early '70s, the market in the US began to develop money market mutual funds with characteristics similar to remunerated sight deposits as a reaction to Regulation Q (ceiling on interest rates that insured depository institutions were permitted to pay to depositors). Several European jurisdictions do not allow funds with the same characteristics (i.e. stable NAV based on amortization costs instead of mark-to-market accounting principles).

${ }^{15}$ Recently, the Securities and Exchange Commission ("SEC") proposed a mandatory transformation of constant-NAV into variable-NAV for some type of money market funds.
} 
accommodative monetary policies) could force the market to develop new and more risky financial instruments.

Policy implication 4: Monitoring should not be limited to specific financial instruments or products, but should also be able to capture the interaction with the economic, legal and regulatory environment. Deregulation and prolonged periods of monetary expansion need strict monitoring and follow-ups.

Product and process innovation: we believe that the traditional distinction between product innovation and process innovation is useful not only from the conceptual standpoint, but also for its policy implications. Indeed, since the crisis, regulators have increasingly supplemented the traditional approach of policy intervention (transparency, disclosure, point-of-sale monitoring, etc.) with an assessment of the design and the features of financial products, regardless of how they have ultimately performed for clients. ${ }^{16}$ Product and process innovation are deeply intertwined. Despite the intrinsic difficulty of separating the two aspects, this distinction is very important from a prudential oversight perspective. As discussed in greater detail below, the creation of a new financial product can generate risks for the producers that are only indirectly (and not necessarily) transferred to the final user. Here again the example of the ETF fits very well: in principle, both physical and synthetic (swap-based) ETFs can generate similar or identical performances for investors (provided that, in replicating the same index, they have the same tracking error); however, they are based on very different processes with potentially different supervisory and prudential implications.

Policy implication 5: A single financial instrument and product can be produced through different processes, all of which the final user is unaware of. It is important, therefore, from the perspective of oversight of financial innovation to have a clear understanding of both product and process innovation. The latter can be a source of operational risk, as well as of other risks. On-site visits to regulated entities could be necessary to collect sufficient information on process innovation.

Theoretical developments are clearly a source of financial innovation. Markowitz's (1954) portfolio theory, Arrow-Pratt's (1963-64) measure of risk aversion, Sharpe's (1964) Capital Asset Pricing Model (CAPM), Fama's (1970) efficiency market hypothesis, Black-Scholes's (1973) and Merton's (1974) option pricing theory, and Ross's (1976) arbitrage pricing theory are some examples. ${ }^{17}$ All of these models are based on a very specific set of assumptions; for instance, they often rely on normal distributions. Until recently, such simplified models were widely used by finance professionals, despite clear empirical evidence that asset returns are often not normally distributed. Modern finance has developed a variety of models dealing with low-frequency highimpact events and with discontinuities; but these new theoretical frameworks (although more robust) are much more complex and computationally expensive. ${ }^{18}$ Even the simplest model extensively used in finance, such as the possibility to capture investors' attitudes towards risk with a single parameter (the Arrow-Pratt measure of risk aversion), has been put under scrutiny. It has been argued that the risk is a much more complex concept that includes other characteristics, such as the degree of prudence and temperance. ${ }^{19}$

\footnotetext{
${ }^{16}$ See FSA(2008); FSA (2011).

${ }^{17}$ Pioneering contributions on several of these developments have been made by Paul Samuelson. See, in this regard, the paper by Merton (2006).

${ }^{18}$ See Rachev et al. (2011).

${ }^{19}$ Analysis of the effects of risk attitudes on economic decisions has typically focused on the impact of risk aversion. Under standard expected utility theory, this amounts to assessing the impact of the second derivative of the utility function. However, many decisions crucially depend on higher order risk attitudes. For example, changes in precautionary saving due to changes in the distribution of a future income stream are determined by individuals' prudence and temperance. Prudence is the sensitivity to risk of the optimal choice of a decision variable. The term "prudence" suggests the propensity to be prepared and forearmed in the face of risk, in contrast to "risk aversion",
} 


\section{Box 2 - The current debate amongst "quants"}

Several financial engineers, or quants, currently hold the view that we need a more holistic, comprehensive and realistic approach to finance. ${ }^{20}$ In addition to the difficulties of taking into account tail risks, skewed distributions and volatility clustering, the crisis shows that it is critically important to properly model the correlations (or, more accurately, dependency structures) between risk factors (see Appendix C).

It is now widely recognized that the copula function is not sufficient to model all types of interdependence, as it cannot explain the dynamics of dependence (i.e. how the dependency of all risk factors - market risk, liquidity risk, counterparty risk, etc. - changes over time). As underscored by Alex McNeil, "I still think some people really haven't got the message that the correlation is just the first in an infinite sequence of numbers that drive interdependence". "[What we need] is a proper understanding of the dynamic of dependence particularly between extreme events". As noted also by Damiano Brigo, "the paradigm of western scienceof analyzing pieces separately, then putting them together - does not work here. Everything interacts nonlinearly, so we really need to understand the theory of multivariate processes". ${ }^{21}$ Therefore, overconfidence in using new theoretical models should be tempered with an awareness that the models are necessarily based on simplified assumptions. This reflects the fact that the real world is complex and its properties cannot be fully explained in terms of individual components and their relationships. In addition, where probabilities are unknown and uncertainty dominates, a measurable risk metric is not available or is difficult to estimate. ${ }^{22}$ From the current debate, it is clear that there are many open questions, both theoretical and computational, and that a much more cautious approach to relying on current financial models is necessary.

Market conditions and theoretical development: theoretical developments are often driven by the emergence of new market conditions that make the adopted theory unsuitable. ${ }^{23}$ For example, until recently, classical derivative pricing theories widely used the assumption that one can borrow and lend at a unique risk-free rate. ${ }^{24}$ In practice, this is no longer true; since the crisis, different aspects are increasingly being taken into account to set up a proper pricing framework: funding, liquidity, credit and counterparty risk. Practitioners have begun to develop valuation formulas for derivative contracts that try to incorporate the modern realities of funding and counterparty risk, which deviate significantly from the risk-free textbook assumptions. Similarly, in response to the crisis, the classical pricing framework, based on a single yield curve used to calculate forward rates and discount factors, has been abandoned, and a new modern pricing approach is prevailing among practitioners, one that takes into account the market segmentation as empirical evidence (e.g. Euribor-OIS spread, FRA rates-forward rates spread, and basis swap spread) and incorporates the new interest rate dynamics into a multiple curve framework (see Box 2). ${ }^{25}$

Policy implication 6: Regulators should have a deep understanding of the theoretical developments generated by financial innovation. In particular, while maintaining a frank dialogue with market players, they should develop an independent opinion of the model's underlying assumptions and of their implications for intermediaries and the economy at large. Besides the specificities of various

which describes the extent of dislike for risk and the desire to avoid it where possible (Kimball, 1990). "Temperance" reflects moderation in accepting risk. As observed by Kimball: we have a hedging position "when an unavoidable risk affects the freely chosen quantity of investment in another risk due to a correlation between the two risks. But it is reasonable to think that an unavoidable risk might lead an agent to reduce exposure to another risk even if the two are statistically independent. This tendency can be called temperance, in the sense of moderation in accepting risks" (Kimball, 1992, p. 162). See also Noussair et al. (2011).

${ }^{20}$ Carver (2012) provides an interesting overview of the methodological problems that quantitative finance experts face in dealing with the complexities posed by the financial crisis.

${ }^{21}$ For the quotations in this paragraph, see Carver (2012).

${ }^{22}$ For an interesting discussion of the use (and limitations) of mathematics in finance, see Focardi and Fabozzi (2009).

${ }^{23}$ See Brigo et al. (2013) and references therein.

${ }^{24}$ See Piterbarg (2010).

${ }^{25}$ See Bianchetti and Carlicchi (2011). 
models, it is important that both intermediaries and regulators be aware of the limitations of the most widely used models and their underlying assumptions (see Appendix C).

\section{Financial innovation and sub-optimal outcomes: when to intervene?}

Market and regulatory failures: like any regulatory framework, policy intervention should be underpinned by a comprehensive overview of various potential market failures and by an appropriate evaluation of possible regulatory failures, which refer to any post-implementation outcome that deviates negatively from what was expected (see Appendix A).

Market failures arise when the free action of individuals in the market does not lead to an optimal allocation of resources (through the price mechanism) in the production process or in consumption; the most common forms of market failure are asymmetric information, externalities, imperfect competition generating excessive market power and supernormal profits, and market incompleteness for all contingent claims. In financial markets, such market failures are not only a cause of inefficiency for single entities, but also a source of instability (contagion) when they assume the form of systemic negative externality among intermediaries.

Market failures in trading innovative products: the retail sector. We know that if consumers are not fully informed or are not able to maximize their expected utility and inter-temporal plans, they can produce sub-optimal outcomes. A notable case is when consumers lack access to information (incomplete or asymmetrical information), for example about the solvency of financial institutions. Incomplete information can lead consumers to buy unfair products, for instance, because they are mispriced or have an embedded implicit fee.

A very different situation arises when agents have bounded rationality: even if fully informed, they are often not able to optimize their financial decisions, either because of computational difficulties (due to excessive complexity) or because of cognitive biases. ${ }^{26}$

i) In standard economic theory, individuals make choices maximizing a utility function, using and processing appropriately all available information. Individuals' preferences are assumed to be time-consistent, affected only by their own payoffs, and are independent of the context (or "framing") in which such decisions are taken. The literature on behavioural economics, however, suggests that individuals often deviate from the traditional models because they have non-standard preferences, incorrect beliefs and systematic biases in their decision-making process. ${ }^{27}$ The context and the framing of the situation matter: two equivalent decision problems that are framed differently may elicit different responses. ${ }^{28}$ In many decision problems, "loss aversion" induces a bias that favours retaining the status quo over other options. Moreover, individuals often underestimate the probability of negative events; beliefs are affected by systematic overconfidence, by overinference from past events, and by overprojection of current tastes on future tastes. A better understanding of the above behavioural biases helps the financial conduct regulators to detect and remedy problems

\footnotetext{
${ }^{26}$ On consumer financial behaviour, see Guiso and Sodini (2012).

${ }^{27}$ For an overview, see S. DellaVigna (2009). This approach has recently been adopted by the Financial Conduct Authority (2013).

${ }^{28}$ According to Tversky and D. Kahneman, the outcomes of risky prospects are evaluated by a value function that has three essential characteristics: reference dependence (the carriers of values are gains and losses defined relative to a reference point); loss aversion (the function is steeper for losses than for gains); diminishing sensitivity (the marginal value of both gains and losses decreases with their size). An immediate consequence of loss aversion is that the loss of utility associated with giving up a valued good is greater than the utility gain associated with receiving it. (see A. Tversky and D. Kahneman 1991).
} 
arising from not fully rational economic agents. For instance, the regulator could require a more effective and fair disclosure, where different options are framed fairly and not so as to lead the consumer to make a wrong choice. ${ }^{29}$ While this is an interesting path, we should be aware of the difficulties that the regulator could face in further expanding the scope of interventions. As observed by A. Tversky and D. Kahneman (1991, p. 1058): "We conclude that there is no general answer to the question about the normative status of loss aversion or other reference effects, but there is a principled way of examining the normative status of these effects in particular cases". 30

ii) Non-rational behaviour such as over- and under-reactions has been extensively considered by financial analysts as well and has implications for the efficiency of financial markets. ${ }^{31} \mathrm{We}$ know that if the equity market is efficient, market prices should tend to be equal to the expectation of the present value of all future dividends, discounted at the appropriate risk-adjusted cost of capital and conditional on all available information. However, in the real world, a number of factors can explain short-term deviations from such highly stylized market conditions. In principle, even without relying on forms of fully optimizing behaviour (but simply on trial and error) such deviations should disappear in the long run as the arbitrage mechanism should wipe out all profit opportunities. This mechanism, however, relies on the assumption that market forces are sufficiently powerful to overcome not only any type of behavioural bias (over- and under-reactions, herding behaviour, sudden shifts of risk aversion, etc.), but also the uncertainties caused by an everevolving environment. In order to deal with some of these problems Andrew Lo (2004) and other authors, inspired by the work of Herbert Simon on bounded rationality and by the analysis of Edward Wilson on sociobiology, suggested using the "adaptive market hypothesis", in which the cyclical changes in risk preferences (and therefore the risk premium) are shaped by the forces of natural selection (to explain or endogenize not fully rational behaviour). ${ }^{32}$

iii) Another stream of behavioural models has tried to explain the wide and persistent deviations of asset prices from the discounted value of expected future cash flows (asset bubbles). For example, a new generation of behavioural models tried to offer new insights into how bubbles start, under what conditions they might burst, and why arbitrage forces may fail to ensure that prices reflect fundamentals at all times. ${ }^{33}$

The policymaker should help individuals by reducing at least some forms of behavioural bias; this can be done, for instance, by asking the financial providers to reorganize the context in which people make decisions (or choice architecture) so that they overcome their cognitive biases and are in a position to enhance their self-interest. According to this approach (called "soft libertarian paternalism"), the framework of the choice is such that cognitively constrained individuals are prompted to make better choices. This type of paternalism is called "soft" because individuals remain free to opt out of the choices deemed optimal by the benevolent designer of the policy

\footnotetext{
${ }^{29}$ See FCA (2013).

${ }^{30}$ As observed by Shiller (1999), while it is difficult to find systematic patterns of behaviour that can be codified in a general theory, we cannot say that "anything can happen" in financial markets; moreover, "it is critically important for research to maintain an appropriate perspective about human behaviour and an awareness of its complexity" (Shiller 1999 p. 1334).

${ }^{31}$ For an overview of sub-optimal behaviour and its implications for the efficient market hypothesis, see Shiller (1999). According to Fama (1998) most of the above anomalies (such as long-term under-reactions or over-reactions to information) can reasonably be attributed to chance. Moreover, according to Fama, these studies rarely provide a test of specific alternatives to the market efficiency hypothesis.

${ }^{32}$ See Lo (2005). While these developments are very interesting, they do limit the analysis to finance theory. A policymaker has to overcome the serious limitation that, in the real world, wide and prolonged deviations from equilibrium in the financial markets (driven by behavioural biases) have serious effects on the real economy (through a number of channels, from welfare effects to public finance) which, in turn, can trigger second round effects on those markets.

${ }^{33}$ For a recent survey, see Scherbina (2013).
} 
framework $^{34}$ (see Section V, Box 5 for a discussion of a strong libertarian approach). The policy suggestion (called "nudging") is to reorganize the context in which people make decisions so that their behaviour is altered in a predictable way without ruling out any options. According to some authors, however, the limit of this approach is that nudging is not capable of sustaining long-term behavioural changes that are rooted in deep individual attitudes and values. ${ }^{35}$

Policy implication 7: Transparency, disclosure of information, and consumer education are the typical policy responses to the above market failures on the consumption side. In order to minimize potential reputational risks and protect consumers, banks offering complex financial products need to have a good understanding of the main problems generated by insufficient awareness of the risks borne by retail investors; they should therefore perform a client suitability assessment. The regulator should encourage the bank to reduce unnecessary over-complexity and to frame different options.

Market failures in trading innovative products: the wholesale sector. In principle, financial innovation should not produce side effects for other banks, the risk of which should be mitigated by the fact that banks are (or should be) much better informed and better equipped to understand complex financial products. However, the crisis shows that even supposedly well-informed and sophisticated banks can buy large amounts of complex mispriced products (such as CDOs-squared), generating idiosyncratic and systemic risks. This can be explained, for example, by over-reliance on inadequate financial models and/or on ratings, caused in turn by moral hazard, wrong incentive schemes, and unaccountability.

Complex securitization products: before the crisis, several banks in some jurisdictions produced large volumes of complex securitization products through sponsored vehicles resulting in unexpected liquidity and credit risks for the sponsor. Large amounts of mispriced and misrated securities were sold to other banks or to consumers (through mutual funds). Structured products were re-used as collateral in the repo market to secure funding in order to set up highly leveraged positions. ${ }^{36}$ All these factors were a source of systemic instability amongst highly interconnected financial intermediaries both in the banking sector and in the shadow banking system. ${ }^{37}$

The mispricing of structured products is not only detrimental to investors, it can also be a source of reputational and legal risks for banks. Mispricing is normally calculated as the deviation between the theoretical value of the security (sum of the value of the security plus the value of the derivative component) and its issuing value. This deviation can be the result of explicit fees (covering mainly production costs) plus a mark-up (implicit fees). Lack of competition or informational asymmetries between consumers and producers can be the main source of extra-profits and implicit fees.

Policy implication 8: In principle, well-informed and sophisticated intermediaries should buy, and be able to manage, complex innovative financial products. Since, in reality, this was not the case -

\footnotetext{
${ }^{34}$ For a short overview, see Thaler and Sunstein (2003).

${ }^{35}$ See (albeit in a different context) Salazar (2011).

${ }^{36}$ Rehypothecation (or re-use of a client's collateral) can in some circumstances be a source of risk: during the time the account provider exercises its rehypothecation right, the client's ownership right is replaced with a contractual right to the return of equivalent securities; this contractual right is not usually protected (MIFID, for instance, protects only the client's ownership rights). This works well until bankruptcy occurs; if the account provider defaults, clients with a mere contractual claim become unsecured creditors, meaning that their assets are, as a rule, tied in the insolvency estate and they are obliged to line up with all the other unsecured creditors to receive them back (see EU, 2012). This problem shows how important it is to have a comprehensive approach where both financial and legal aspects (and their evolution) are taken into consideration.

${ }^{37}$ Rules on securitization, complemented by a wide regulatory perimeter, have allowed some jurisdictions to contain the harmful effects of financial innovation and limit the request for public support that has been particularly high in some countries (see European Commission, 2011). For a recent short description of the crisis, see Liikanen (2012).
} 
as emerged during the recent financial crisis - regulators should set up an adequate quantitative monitoring framework (eventually through centralized data repositories) to intercept anomalies or concentration of risks generated by complex innovative financial products (see Section VI on monitoring), and use such information for developing early warning indicators.

\section{Box 3 - On mispricing and its effects}

Problems of mispricing also affected (even before the crisis) structured financial products other than securitizations. As mentioned before, structured products are a combination of elementary instruments from the spot and futures markets (e.g. stocks, interest rate products, derivatives) promising tailor-made risk/return profiles for investors. They offer the feature of facilitating complex positions in options without the need to access options exchanges. When structured products are traded, transaction costs (e.g. bid-ask spreads) and commissions for the private investor are usually lower than those for the corresponding single trades. In practice, however, the price can deviate from the "fair value" along the life of the security. Some authors show that the mispricing is generally in favour of the issuing institution, and differs among the issuers as well as among the types of instrument. In general, more complex products incorporate higher implicit premia. In the secondary market, however, the level of overpricing tends to decrease as the products approach maturity. ${ }^{38}$

Structured securities or transactions are often bespoke products and their valuation depends on proprietary financial models and the inputs that drive them. Frequently, such inputs are not directly observable in the market. As recognized by the CRMPG III representing important market players, ${ }^{39}$ even a valid model with accurate inputs will not always capture the immediate supply and demand profile of the market, meaning that the model price will not always determine the price at which a transaction occurs. In these circumstances, buyers and sellers may achieve price discovery only through actual transactions, but these, in stressful market conditions, may not occur because of the illiquidity of products. The CRMPG III recognized that during the crisis "many high-risk complex financial instruments presented significant challenges for risk monitoring and management systems, which struggled to keep up with the complexities of product design and development and, in particular, encompass the risk that hedging strategies were ineffective, so generating additional, and sizeable, exposure in the form of basis risk". "Moreover, "in addition to differences in valuation methodologies, causes of pricing discrepancies included a lack of adequate infrastructure by some industry participants. As a result, some large integrated financial intermediaries were not able to analyze positions on a timely or comprehensive basis" (CRMPG III, p. 87). Once the market realizes that a class of asset is substantially mispriced, then the adjustment assumes the form of a sudden and wide correction.

The CRMPG III also noted that "large integrated financial intermediaries typically attempt to optimize performance subject to liquidity, rating agency, regulatory capital, accounting, and other parameters. This can encourage behaviour which, when taken across an industry as a whole, can prove highly pro-cyclical. This is particularly the case given industry participants' tendency to mirror each other's trading strategies, and their requirement to unwind positions on a simultaneous basis during periods of market stress" (CRMPG III, p. 89).

Potential sub-optimal behaviour relating to process innovation. The financial crisis offers clear evidence that widely used market models have failed to properly consider correlations between extreme (rare) events. Market participants should be aware of the limits of models or product design, and not be overconfident in view of the following potential problems:

\footnotetext{
${ }^{38}$ See Stoimenov and Wilkens (2005).

${ }^{39}$ The Counterparty Risk Management Policy Group (CRMPG) is a private sector initiative launched by a number of large banking and financial global players and coordinated by G. Corrigan (Goldman Sachs) and D. Flint (HSBC).

${ }^{40}$ See CRMPG III, (2008), p. 56.
} 
i) Inaccurate selection of the financial model with respect to the tasks or objectives. Appropriateness of model selection is critical. If the model is not well-designed (because it is based on simplistic assumptions, is unable to deal with tail risks, volatility clustering, etc.), it can produce wrong valuations and mispricing. Complexity, excessive leverage, illiquidity, and interconnectedness can exacerbate the negative effects of mispricing;

ii) Misuse of the selected model: even the most perfect financial model can produce undesirable results if not adequately used. Insufficient datasets or time series (small-sample problem ${ }^{41}$ ), poor data quality, missing data or outliers, and mis-calibration are some of the most frequent problems;

iii) Imperfect algorithms: a different set of problems relates to the generation of errors or malfunctions due to imperfect numerical routines (e.g. flash-trading programmes);

iv) Imperfect legal design: this can produce significant legal or reputational risks and even systemic risks (for instance, ill-designed contractual triggers or covenants).

v) Non-robust market infrastructure: good market functioning is essential for preserving market confidence. More transparency and liquidity, which enhance market price discovery, improve the allocation of financial resources. A robust and well-regulated market infrastructure (supported by Central counterparty clearing houses (CCPs)) helps to contain pro-cyclicality, cliff effects, and other forms of market misbehaviour.

The following Table 1 illustrates the above aspects (see next page).

\footnotetext{
${ }^{41}$ The use of optimal sample size in calibrating pricing or risk models is not trivial: generally, large samples result in reduced sampling error; however, if market characteristics are changing, a small sample emphasizing recent data or (even better) the use of adaptive state-state models or GARCH models may be preferable. They are, however, computationally more demanding. See Sheedy (2009).
} 
Table 1

- Retail sector

\section{Process innovation:}

\section{i) type of problems}

- Model selection

- Model application

- Algorithm / routines

- Legal design

ii) possible causes

- Misbehaviour

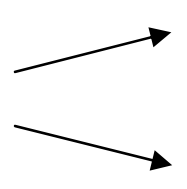

Mispricing, use of simplistic assumptions

Inadequate analysis of tail risks

(counterparty risk, liquidity risk, etc. and their dependence structure and dynamics)
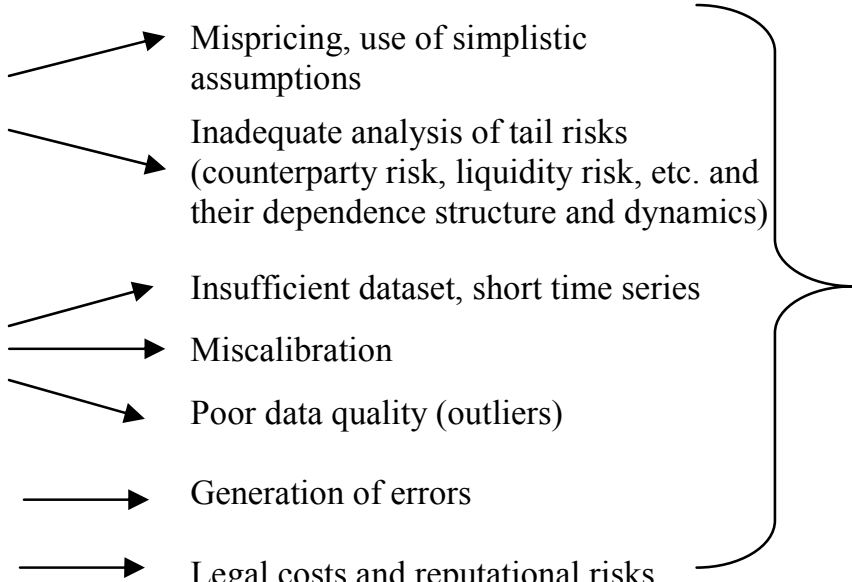

Poor risk

analysis or mispricing of new products

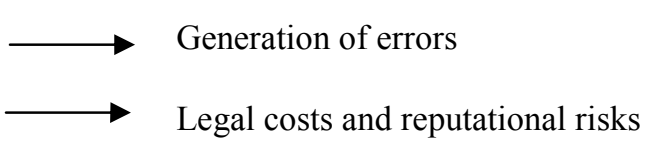

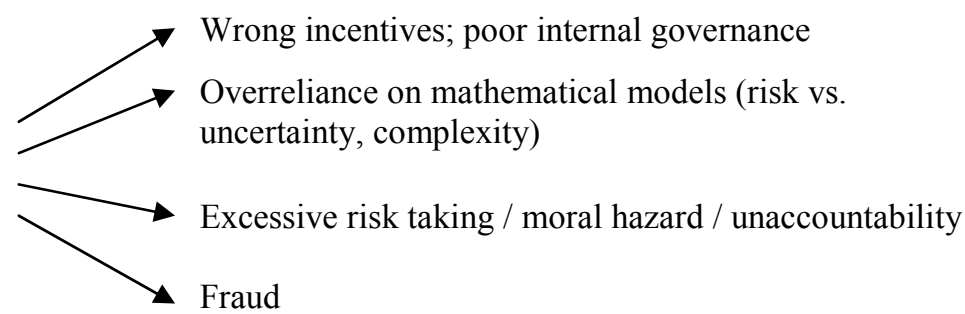

- Market infrastructures (e.g. use of CCP to mitigate counterparty risk, reporting OTC derivative contracts to centralized trade repositories, etc.) $\rightarrow$ close cooperation with financial market regulators. 
Overreliance on simple models: complacency and overreliance on financial models have historically been related to the misbehaviour of agents involved in sophisticated financial products, in some cases without top managers or boards being fully aware. This is of great importance if we consider that, according to some authors, the crystallization of tail risks may threaten the financial stability of even highly-capitalized intermediaries. ${ }^{42}$

Policy implication 9: It is reasonable to think that in a competitive and not excessively concentrated market, inefficient agents are progressively forced to reduce their role or even to leave the market. However, persistent use of wrong models and model misuse emerged as a standard at the outset of the financial crisis. Regulators should focus their attention on incentive misalignments, unaccountability, moral hazard, and insufficient internal controls that may, through financial innovation, induce excessive risk taking. Sound internal governance and in particular the New Product Approval Policy (see Section V and Appendix D) could reduce the appearance of new types of risk. Regulators should expect an intermediary to analyse all risk factors and consider all possible scenarios when designing a new product as well as to assess model assumptions. The assessment should be included in the information communicated formally to the Board and senior management. On-site supervisory visits should verify that the process is properly enforced.

\section{Possible policy outcomes}

From the above overview of financial innovation it is possible to draw a set of general principles and policy implications.

A - General principles - A regulatory framework for financial innovation should respect the following four general principles:

i) Preserve the stimulus to innovate, maintain the positive aspects of financial innovation while minimizing unintended side-effects;

ii) Discourage unnecessary over-complexity of financial products. The regulation should be consistent with this principle;

iii) Promote consistency across institutions and instruments in order to minimize the risk of regulatory arbitrage;

iv) Maintain cultural independence, keeping an open-minded, holistic and critical approach in order not to be guided by conventional wisdom, such as the presumption that markets are efficient and necessarily self-stabilizing. ${ }^{43}$

B - Policy implications - Summing up, our analysis suggests the following policy implications:

1) As financial innovation involves a number of deeply intertwined economic functions, close cooperation between banking and financial regulators is particularly important.

2) The scope of the policy action should include both banks and shadow banking entities or activities as defined by the FSB.

\footnotetext{
${ }^{42}$ See, for example, Ratnovski et al. (2011).

${ }^{43} \mathrm{See}$, in this regard, FSA (2009). On regulatory consistency and financial innovation, see Bernanke (2007). See also Visco, 2012 and 2013.
} 
3) In order to keep up with market developments, the regulators should make extensive use of market intelligence and interviews.

4) Particular attention should be paid not only to financial innovation, but also to the economic and normative environment, taking a forward looking and holistic approach. Deregulation and prolonged periods of monetary expansion need strict monitoring and follow-ups.

5) Both product and process innovation are important; the latter should be monitored through extensive use of on-site, targeted visits or inspections. The regulator should discover the fundamental driver of financial innovation, analysing its economic rationale and functions.

6) Regulators should keep up with theoretical developments. They should encourage intermediaries to have a clear understanding of their limitations in dealing with new financial models and underlying assumptions.

7) Regulators should promote transparency, disclosure and financial literacy. They should encourage the intermediaries to reduce unnecessary over-complexity and to introduce product suitability assessment.

8) Regulators should set up a quantitative monitoring framework based on centralized data repositories in order to collect data on structured products and their characteristics. They should design early warning indicators to intercept anomalies or concentrations of complex financial instruments.

9) Appropriate internal governance should reduce the misuse of financial models, distortive incentive structures, unaccountability, and unethical practices. Regulators should also expect an intermediary to analyse all risk factors and consider all possible scenarios when designing a new product. On-site visits should verify the adequacy of the enforcement.

\section{Policy tools}

A strong and effective legal and supervisory system, designed to protect economic agents from unfair or illegal practices (fraud, abuses, etc.) and market misconducts, is essential. This, in the long run, will pave the way for the sound and sustainable growth of banks. Competent authorities can use a broad range of regulatory and supervisory tools to deal with the above problems. The subject of this section, however, is not individual rights, but rather the definition of policy tools to deal with economy-wide market failures, generating inefficiencies and social welfare costs.

The proposed taxonomy is based on seven policy tools (PTs) able to capture the nine policy implications listed above. They are broadly consistent with the EU Regulation establishing the EBA (Regulation (EC) No. 1093/2010, particularly Article 9, and EBA Guidelines on Internal Governance). They are inspired by the G20/OECD high-level principles on financial consumer protection, by the FSB recommendations on good supervision, and by the BCBS guidelines on corporate governance, adapted to take account of the specific characteristics of the financial innovation, which, as we have seen, have several implications also from a prudential point of view. ${ }^{44}$ They take into consideration recent ESMA (2012a, 2012b) guidelines on related issues as well. The taxonomy is ordered by the intensity of potential market failures, namely: asymmetric

\footnotetext{
${ }^{44}$ See OECD (2011); FSB (2012); FSB (2011b); BCBS (2010); see also Appendix B.
} 
information, behavioural biases, principal-agent problems, non-systemic risks or limited negative externalities, systemic risks and serious market threats. Some of these policy responses are, to some extent, intrusive, possibly generating unintended side-effects, such as false alarms, altered preferences or risk-profiles and, more in general, inefficiencies. The policy intervention should therefore be calibrated on the basis of an adequate and sensible cost-benefit analysis. In the case of financial innovation, this is a particularly difficult exercise, as it is very hard to evaluate the longterm net benefits of policy intervention.

Transparency and disclosure (PT 1): this set of policies aims to reduce information asymmetries between consumers and banks. Greater disclosure and transparency is the pre-condition for any rational consumer to take responsible and well-informed decisions. Transparency and disclosure also help to enhance market discipline and reduce possible misalignments between fair and actual asset valuations (i.e. the level of mispricing), improving both asset allocation efficiency and consumer welfare. Standardized pre-contractual forms and comprehensive cost indicators should make information also accessible to less-educated consumers and allow a comparison between similar products. Specific disclosure mechanisms should be developed to provide information commensurate with the complexity and riskiness of the product or service. The provision of advice should be objective and based on the consumer's profile, considering the complexity of the product, the associated risks and the customer's financial objectives, knowledge, capabilities and experience. If the product is particularly complex and innovative, the financial agent or advisor should have an adequate and deep understanding of its features and potential risks.

Awareness and financial education (PT 2): the competent authorities should take a variety of measures to enhance the financial literacy of consumers. The objective is to help them make responsible choices in line with their attitude to risk, liquidity constraints, financial needs and intertemporal plans. It could be useful to promote the understanding of basic economic concepts, as well as the diffusion of simple financial tests (such as the certainty equivalent test), to help individuals reveal their own risk preferences and level of risk tolerance. Consumers should be aware that financial markets can be highly volatile and characterized by the crystallization of rare, high-impact events. Appropriate policy responses should be developed to help consumers enhance their knowledge, skills and confidence to understand the risks and opportunities of a given product or service. Consumers should make informed choices and take effective action to improve their own financial well-being. Financial service providers should nevertheless assess the related financial capabilities, situation and needs of individual customers before agreeing to provide them with a product, advice or service. The policy intervention should also help consumers reduce at least some forms of behavioural bias and improve their financial responsibility. This, in turn, produces positive feed-back on the intermediaries, which are the main objective of our analysis.

Internal governance (PT 3): well-organized governance is essential for a safe and sound functioning of financial institutions and, if not implemented effectively, may adversely affect that institution's risk profile. Sound internal governance also helps to protect depositors, consumers and other clients; it can help to reduce moral hazard and principal-agent problems. ${ }^{45}$ The problems relating to mispricing, imprudent use of financial models, operational and legal flaws or fragilities, and inappropriate risk management (in particular, excessive leverage, liquidity and counterparty risks) associated with innovative financial products, require specific attention, above traditional standards. The two main internal governance functions dealing with financial innovation are Risk Management and Internal Control. The first requires an institution to have in place effective processes for identifying, measuring or assessing, monitoring, mitigating and reporting on risks. The second requires institutions to have an appropriate internal control framework to develop and maintain systems for ensuring effective and efficient operations, adequate control of risks, prudent

\footnotetext{
${ }^{45}$ See BCBS (2010).
} 
conduct of business, reliability of financial and non-financial information reported or disclosed (internally and externally), as well as compliance with laws, regulations, supervisory requirements and the institution's internal policies and procedures (EBA, 2011, Title III, Section 3 (33-34), see Appendix D).

It is important for the internal governance and risk management functions to be performed at firm-wide level: a strong grip on foreign subsidiaries and branches, particularly when they are located in jurisdictions where the regulatory framework is less stringent, is critical. With specific attention to aspects related to financial innovation, we would like to underline that:

a) Senior management and directors should have a thorough understanding of innovative financial products and processes. The competent authorities should engage with Board members, particularly independent non-executive directors and risk managers, to discuss and assess awareness of the characteristics of the most innovative or complex financial products. The Board (especially the independent directors) should be selected on the basis of their understanding of financial innovation and related pricing models.

b) Distortion of managerial incentives or ill-designed remuneration schemes need appropriate policy responses. Compensation schemes should be consistent with prudent risk management and the company's long-term results; ${ }^{46}$ the measurement of performance for bonus awards should include adjustments for all types of risk and the cost of capital and liquidity. ${ }^{47}$ We think that introducing "malus" or claw-back of past bonuses could be considered, for instance when the characteristics, assumptions and implications (for the bank itself and for other contractual counterparties) of a new product or financial contract are not well-represented to the Board and are a source of serious negative effects. ${ }^{48}$ Well-designed incentives can help minimize the negative effects of excessive risk taking and moral-hazard, for instance, when traders generate risks through the production of innovative and complex financial instruments or contracts of which the Board or the shareholders are not fully aware.

c) It is particularly important to review, at the earliest opportunity, outsized profitability and market share gains to ensure that this does not reflect a problem with the original pricing or risk assessment of the product. Similarly, it is advisable to introduce internal mechanisms to encourage early disclosure of problems related to innovative products.

d) Treating both retail and non-retail clients fairly and so that they are not affected by firm's conflict of interest should be an integral part of good governance.

e) It is important that the assumptions underlying financial models are clearly articulated and subject to frequent, comprehensive review. Alternative measures should be presented to the Board to demonstrate the sensitivity of the calculated metrics to changes in underlying assumptions. Moreover, intermediaries should "think creatively" about how stress tests can be conducted, including the scenarios where a significant stress event is generated by contagion.

f) The intermediary, after offering complex, innovative or highly risky products or services, should promote a post-transaction monitoring and follow-up, such as sending monthly evaluation reports or improving clients' ongoing monitoring systems.

\footnotetext{
${ }^{46}$ This aspect has also been widely considered in the context of the fund industry regulation (UCITS IV - European Commission Directive proposal (COM, 2012, 350 final).

${ }^{47}$ See EBA (2011), Section 21 (5) p. 34

${ }^{48}$ The use of claw-backs has also been considered by the BCBS (2010), principle 11 (112).
} 


\section{Box 4 - The New Product Committee}

The New Product Committee (NPC) is an internal governance device designed to foster responsible innovation and assess the appropriateness of new financial products and activities. ${ }^{49}$

The NPC should be organized as follows: the NPC comprises permanent members (risk, compliance, legal, fiscal, IT, business conduct, remuneration, finance) and invited members (appropriate representatives appointed after discussion with the business sponsor). The Chairman of the NPC, who should be fully independent, is responsible for the final decision (approval of the product or service). The business sponsor, in conjunction with the risk manager, should prepare a document describing the features of the new product and identifying the resulting impact for the bank, including but not limited to the risk management, legal and reputational profiles. Based on this document, members of the NPC have to provide a written statement to the business sponsor justifying their position on the new activity or product under scrutiny. In order to get a new product approved, the sponsor first organizes informal meetings with the different functions in the bank to get their reactions. Initially, once the validation has been granted by the NPC, the approval is valid for a limited period (for instance 12 months). A senior member of the Risk Committee, also a member of the NPC, is responsible for a preliminary assessment of the risks generated by the new product. If the new product has complex derivative components, the NPC should explicitly describe the robustness of the model and the underlying assumptions.

The NPC could be a useful tool to deal with several problems provided that 1) it is not considered a further add-on to the already overcharged internal governance structure of the banks; 2) its role is interpreted as an internal, critical, holistic assessment of potential undesirable risks - for the entity and for the contractual counterparts - of innovative products or activities; and 3) the assessment involves various areas of the bank. The final aim of the NPC framework is to enhance the staff's and the Board's accountability and legal responsibilities.

g) All particularly innovative financial institutions should have a New Product Committee (NPC) (see Figure 2 and Box 4). The NPC should regularly (at least once a year) produce a written statement containing, in addition to the above mentioned aspects of good corporate governance, the following information:

- A clear description of the economic rationale or functions of the new class of products or type of transactions (as described in Section II paragraph 2). Unnecessary overcomplexity of products or transactions should be avoided.

- A clear quantitative representation of the risk profile of the new class of products (see Section VI).

- A synthetic overview and assessment of the characteristics of all the classes of designated structured transactions. ${ }^{50}$ Designated structured transactions are transactions, series of transactions or products where (i) one of the client's principal objectives appears to be to achieve a particular legal, regulatory, tax, or accounting treatment, including transferring assets off balance sheet; (ii) the proposed legal, regulatory, tax, or accounting treatment is materially uncertain; (iii) the product or transaction (or series of transactions) has substantially offsetting legs ${ }^{51}$ or lacks economic substance; or (iv) the product or transaction (or series of transactions) could be defined as financing, but is structured in another manner.

- A synthetic description of the characteristics of all classes of strategic transaction. These include all transactions that are sufficiently large and important to the client or sufficiently large in the context of the market to warrant heightened scrutiny. They often have several of the following features: (i) losses or gains from the transaction could reasonably be expected

\footnotetext{
${ }^{49}$ On the NPC see Armstrong et al. (2011).

${ }^{50}$ This and the following paragraph are based on Goldman Sachs (2011).

51 "Offsetting legs" refers to cash flows under different parts of a transaction (or group of related transactions) which from an economic perspective cancel each other out. Transactions with offsetting legs may lack economic substance.
} 
to impact materially on the client's financial position or adversely on the firm's reputation; (ii) the transaction is likely to have a material impact on the market; (iii) the transaction requires the approval of the client's Chief Financial Officer, Chief Executive Officer or Board of Directors; (iv) the transaction hedges a material acquisition, disposition or other business combination transaction by the client, and the hedge is material; (v) the transaction requires separate disclosure in the client's financial statements or will otherwise be disclosed through a public filing; or (vi) the transaction represents a large financing commitment by the client. Strategic transactions may not involve complexity or unique structural features, but they nevertheless merit heightened review because of the above factors.

- A statement regarding the suitability assessment: ${ }^{52}$ the NPC should assess the suitability of the product or transaction for the following classes of clients: i) retail; ii) professional investors (e.g. banks, broker-dealers, investment advisers and hedge funds); iii) other institutional clients (e.g. municipalities, sovereigns, sub-sovereigns, pension funds, corporations, charities, foundations and endowments); and iv) high net worth accounts (e.g. natural persons, family businesses). The suitability assessment has recently been recommended by IOSCO (2013a), ${ }^{53}$ which advises that intermediaries be required to develop and maintain internal processes and procedures with a view to ensuring compliance with the suitability requirements, ${ }^{54}$ the management of conflicts of interests, the proper conduct of business and the fair treatment of all customers, including in the distribution of complex financial products. ${ }^{55}$ According to IOSCO, effective internal reporting and communication of information should be established at all relevant levels. More specifically, "intermediaries should put in place and enforce written strategies, processes and controls in view to ensure that any financial products they intend to distribute, especially complex financial products, are suitable for the type of customers they intend to solicit. When developing or selecting complex financial products for distribution, intermediaries should establish appropriate ongoing internal processes for identifying, periodically reviewing and approving (or rejecting) the products in order to promote their compatibility with the characteristics and needs of the prospective customers they intend to target". ${ }^{2}$

- An ethical statement: it is widely recognized that reasonable ethical standards are part of good corporate governance.

The board should base its ethical standards on principles shared with other stakeholders. A critical, open minded attitude is important, as conventional wisdom is not necessarily correct and is potentially affected by ignorance, confusion and prejudice ${ }^{57}$. Note that, while it is irrational or improper to ignore well known facts, rational decisions can be taken in situations of uncertainty or partial ignorance. Institutions can adopt different ethical rules, provided that they are simple, transparent, and designed in a manner that is well-specified and verifiable ex-post. Ideally, in order to be universally accepted, the company should

\footnotetext{
52 See European Commission, 17179/12, Proposal for a Directive on markets in financial instruments repealing Directive 2004/39/EC.

${ }^{53}$ See IOSCO (2013a).

${ }^{54}$ According to IOSCO's (2013a) suitability requirements, an intermediary should "assess whether the product being sold matches the customer's financial situation and needs." [This] "may include an assessment of the customer's investment knowledge, experience, investment objectives, risk tolerance (including risk of loss of capital), time horizon and/or capacity to make regular contributions and meet extra collateral requirements, and understanding of the product in question where appropriate" (IOSCO 2013a, pp. 6-7). See also Article 19 of Directive 2004/39/EC (MiFID).

${ }_{55}$ According to IOSCO (2013b), complex financial products are "financial products, whose terms, features and risks are not reasonably likely to be understood by a retail customer (as that term is defined in individual jurisdictions) because of their complex structure (as opposed to more traditional or plain vanilla investment instruments), and which are also difficult to value (i.e. their valuations require specific skills and/or systems, particularly when there is a very limited or no secondary market)." (see IOSCO 2013b, p. 6-7).

${ }^{56}$ See IOSCO (2013a), p. 18.

57 This section adapts some ideas developed by Hare (1989), particularly chapters I, VII and XIII.
} 
maximize the satisfaction of preferences of all fully informed and aware stakeholders, considered impartially (i.e. giving equal weight to all preferences). Some boards could decide to go further, where the long-run marginal consequences of the company's actions for the society are taken into consideration as well. This suggested approach is very flexible: the board could decide to adopt a strict view (i.e. only the effects of the on specific financial markets are considered) or rather a broad view (where the perceivable implications for the real economy are included). While restricting the business possibilities for the company, this very strict policy stance could be beneficial in the long run, not least in terms of public reputation.

In practical terms, the NPC should translate the boards' principles into specific ethical standards. It could decide, for instance, to forbid all speculative transactions unless for hedging a risky position of the firm. Similarly, the NPC could decide to discourage the production of an ETC that, for instance, increases the volatility of a primary good, causing very negative economic effects to some producers (for instance farmers in poor countries specialized in the production of that good). Note that this rule excludes relevant nonutilitarian information (such as motivations, rights or other non-utilitarian ethical values). This means, for instance, that it does not preclude the company selling a very risky product to a fully informed and aware retail customer.

In many circumstances the economic environment is characterized by relevant uncertainty and it is difficult for the NPC to define ex ante the set of possible events or consequences and to apply respective probabilities. In these situations it would be problematic for the NPC to be accountable for the negative externalities generated by the supply of some financial products. The NPC could, however, reduce this problem by releasing a statement based on the following simple application of Harsanyi's criterion, which deals with ethical rules with uncertainty.

According to this criterion, if the NPC wants to decide between two alternatives, A and B, all the NPC's members have to do is to ask themselves the question: "Would I prefer to live in a society conforming to standard A or in a society conforming to standard B? - assuming I would not know in advance what my actual social position would be in either society but rather would have to assume to have an equal chance of ending up in any one of the possible positions". ${ }^{58}$ This rule is fully rational, consistent with utilitarianism, and able to deal with an uncertain environment, where only an ex ante intuition of possible consequences is available.

This framework roots its moral stance on the obligation to consider all available information and to critically assess the nature and implications of the financial innovation. This process needs to integrate two aspects; the first is based on a fully informed and rational analysis, while the second uses the intuition in order to obtain a prudent evaluation of all risky factors. The intuition is particularly important in situations of uncertainty, tension or emergency ${ }^{59}$, for instance due to the perception of potentially unstable market conditions and, more in general, when the NPC is dealing with complex situations.

The ultimate goal of the suggested policy framework is not to promote any specific ethical rule, but rather to force the firm and its bodies to disclose their own criterion and be socially accountable for it. However, should the market, on average, decide to take an ethical stance considered unsatisfactory by the regulators (which should be accountable and appointed

\footnotetext{
${ }^{58}$ See J. C. Harsanyi (1982), p. 46.

59 See Hare (1989), chapter XIII, p. 227.
} 
through a transparent and democratic process), a more intrusive and paternalistic approach is needed (see Box 5 and policy tools 6 and 7).

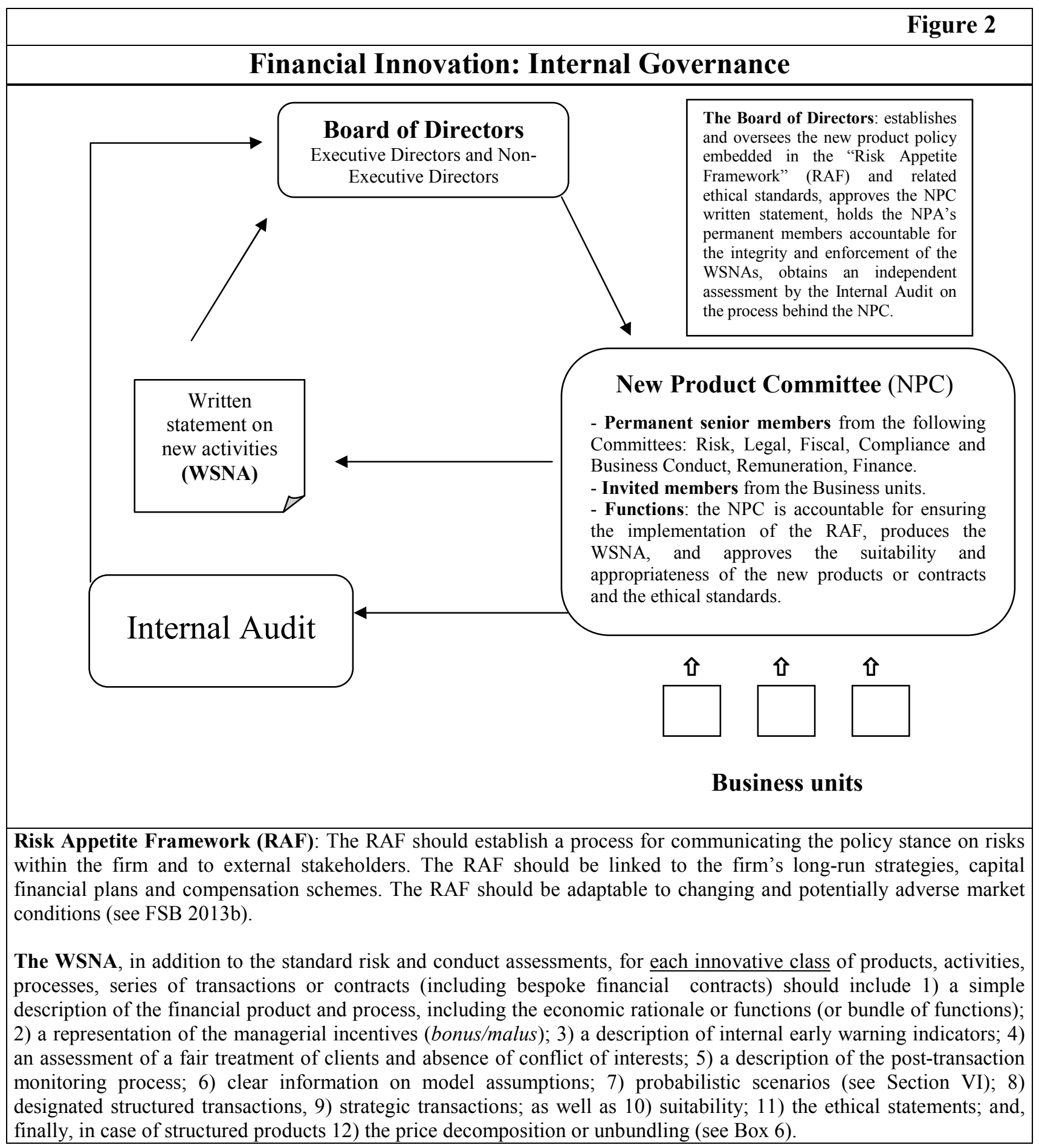

Internal governance could be insufficient: even assuming that all the types of risk mentioned above are properly considered and managed, that all best internal governance procedures have been adopted, and that the design of all incentive schemes perfectly aligns the interests of various stakeholders, there is still a possibility that the firm may be a source of negative unintended systemic externalities for other entities or economic agents. Three circumstances are highly relevant: 1) the single intermediary is unaware of the effects of its behaviour on the system;2) the single intermediary is aware that it is generating a possible negative externality, but it considers that such action has negligible consequences; and finally 3 ) the intermediary behaves as other players in 
the market and is aware that the market is generating a negative externality even on its economic condition, but a coordination failure prevents self-correcting action. More policy interventions are therefore needed, and in particular:

Warnings (PT 4): in some circumstances, specific banking and financial products can generate serious and undesirable risks for a significant portion of the household sector or other intermediaries, directly or indirectly affecting a certain part of the economic system. The competent authorities should consider a more incisive approach, releasing a general warning regarding the diffusion of a specific financial product. The objective of such warnings is to encourage financial prudence (on the part of both consumers and intermediaries). This policy option should be considered where a specific product is a source of serious threat ${ }^{60}$ for some market segments or the financial market as a whole. In the case of a false alarm or welfare loss for the producers, account should be taken of the potential reputational and legal risks to the regulator.

Financial market standards (PT 5): in some cases, the competent authorities should consider developing appropriate technical standards. The case of securitization offers a clear example: as we have already discussed, the market evolution of this instrument degenerated, in some jurisdictions, into the production of complex, opaque and mispriced products. Regulators and standard setters are now discussing several policy responses: ${ }^{61}$ i) better transparency by issuers about verification and risk assessment practices; ii) review of investor suitability requirements and development of tools to assist investors in understanding such instruments; and iii) better incentive schemes, based on the principle of more retention of risks by the issuers (called "skin-in-the-game"). This approach should align the compensation arrangements with long-run performance and asset quality. Where appropriate, the regulator should also develop standards to promote simple, comparable and uniform securitization products and to support the market in developing a trading platform. This should enhance liquidity and price discovery.

Restrictions or temporary prohibitions (PT 6): in specific circumstances, the competent authority, after an in-depth empirical analysis, could consider whether to restrict or even temporarily prohibit a financial product. The main policy objective of the restriction or ban should be to prevent systemic risks and to protect the consumers or depositors. The theoretical justification for this option is to preserve the system from economy-wide negative externalities. This rather coercive approach is particularly useful in circumstances where the potential serious threat consists in the sudden crystallization of risks, with a rapid and significant dislocation of assets, runs, or wide price changes (cliff effects); the restriction on naked short selling is an example.

Product pre-approval (PT 7): ${ }^{62}$ in principle, the policymaker could contain the harmful effects of financial innovation by implementing a process of regulator pre-approval of all innovative financial products. On the basis of the discussions so far, we think that the regulator should be very cautious in deciding to be responsible for vetting products or assessing pricing models. There are various reasons for this: i) the evolutionary nature of the phenomenon implies that the regulator always lags behind market developments; ii) intervention could stifle market initiatives to promote innovative financial products; and iii) enforcement could be very difficult and costly. More importantly, even assuming that all these problems are overcome, two critical aspects remain unresolved: the policy option is not compatible with the incentives (generating moral hazard by both producers and consumers); the reputational and legal risks for the regulator could be very high. For these reasons, while not ruling out the possibility of introducing pre-approval in specific cases, we are more in

\footnotetext{
${ }^{60}$ While preserving flexibility, regulators should provide a shared view of the meaning of "serious threat" (terminology used, for instance, by both EBA and ESMA).

${ }^{61}$ See IOSCO (2012a).

${ }^{62}$ On these aspects, see FSA (2011)
} 
favour of making extensive use of transparency, monitoring, on-site inspections, and very stringent internal governance rules.

\section{Box 5 - A strong paternalistic approach}

Product restrictions or bans designed to protect consumers could be considered in cases where specific products can generate serious losses to a large number of consumers or investors. As discussed above, people do not always make rational choices; individuals can make poor decisions, especially if they have behavioural biases or limited capabilities with respect to the complexity of the problem. In such circumstances, a policy option could rely on the strong paternalism principle, according to which a policymaker intervenes in the choices of individuals (with no opt-out) for their own good, making them better off in their own opinion, free of behavioural bias. However, proper calibration is needed to avoid a situation in which the policymaker interferes in individuals' decisions in a coercive or restrictive manner, reducing their fundamental choices and freedoms. Such intervention should be considered only in cases of clear behavioural bias or excessive risk taking. While this policy option almost certainly creates a negative effect on suppliers of the financial product (at least in the short run), it should produce a net social welfare gain. Such developments, however, would open the door to a number of very complex issues beyond standard utilitarianism. The following observation by J. A. Mirrlees is interesting in this regard "[i]t must be legitimate, in principle, to advance arguments in favour of modifying the utility function that exactly represents my existing tastes. It cannot be wrong in principle to try to get someone to do what would be better for him even though he does not recognise it: but there must be some basis for saying that, with full understanding, he would come to accept the rightness of the altered utility function, or, rather, the underlying preferences". 63

The introduction of a financial innovation authority: Some authors have proposed the introduction of a specific authority in charge of approving each single financial product, building on the analogy of the American Food and Drug Administration (FDA) ${ }^{64}$ Under this proposal, the sponsoring financial institution would submit an application to market a new financial product: "It will be required to pay a significant fee that will fund the cost of testing. The sponsor will provide a Safety and Effectiveness Statement, which will include comprehensive information concerning the nature of the product, the marketing plan (e.g. to whom it will be marketed, etc.), what the functions of the product are, and then evidence that the product will serve these functions. In addition, the sponsor will provide the results of safety tests based on its internal models, including the structure, inputs and assumption guiding these models. Unlike current practice, however, the models cannot be proprietary". Moreover, the sponsor would be required to provide the Authority with full code information about the models, so that the latter could replicate the studies and understand their meaning. The sponsor would also be asked to provide information for a Financial Stability Impact Statement. Whereas the Safety and Effectiveness Statement would focus on the risk impact on the sponsoring institution and on the buyer of the financial product, the Financial Stability Impact Statement would focus on the impact of this product on the financial stability of the system as a whole. The proposal is based on the precautionary principle adopted by various international bodies (such as UN agencies), which states that "if an action or policy has a suspected risk of causing harm to the public or to the environment, in the absence of scientific consensus that the action or policy is harmful, the burden of proof that it is not harmful falls on those taking an act". ${ }^{65}$

\footnotetext{
${ }^{63}$ Mirrlees (1982), p. 69.

${ }^{64}$ See G. Epstein, J. Crotty (2009); J. Crotty, G. Epstein (2009).

${ }^{65}$ See J. Crotty, G. Epstein (2009). Other authors have had the idea of setting up a similar authority which should, however, adopt the rule of approving only products that are socially beneficial, defined as financial instruments that help people insure against or hedge risks (in contrast with products used for gambling, considered socially detrimental). See E. Posner, E. Weyl (2012).
} 


\section{Monitoring in practice}

While monitoring is a fundamental aspect of the surveillance of financial innovation, disclosure is equally important because it is the basis for market discipline. Regulators should contrast the natural tendency of market players to avoid the disclosure of comprehensive, granular information. At the same time, the information collected should be robust, treatable, and strictly consistent with the supervisor's regulatory objectives. The monitoring process set up by regulators should include the following five stages:

i) Ongoing market monitoring - building upon a set of early warning indicators (based on market data) and a well-structured cycle of interviews with dynamic and innovative market players, the regulator can intercept potentially harmful forms of financial innovation at an early stage. This activity, however, is insufficient. In order to have more robust empirical evidence, the regulator should consider implementing a system-wide data repository. One possibility is to expand the information currently released by issuers to the relevant National Numbering Agency (NNA) in order to obtain the ISIN number. ${ }^{66}$ In particular, the competent authority should have the power to collect, by means of the NNA, all relevant information on each single non-equity financial product (type of financial instrument issued or offered, notional value, yields, maturity, net funding cost, rating, currency, etc.). ${ }^{67}$ Moreover, for products with at least a derivative component, in addition to their characteristics, it could be necessary to have the unbundling of the value of various components (as percentage of the issuing price): value of the bond, value of the derivative component, value of the both implicit and explicit fees. ${ }^{68}$ The regulator should also collect information on all complex structured products (see Box 6). All type of entities (banks, "shadow banks", other financial intermediaries, public and private non-financial corporations) should provide the above information for the whole group, including foreign branches and subsidiaries. An alternative approach more centred on the disclosure of risks rather than complexity and innovation, is based on the probabilistic performance scenarios. ${ }^{69}$

ii) Initial assessment and selection of topics - if the preliminary analysis points in the direction of further investigation, the unit in charge of monitoring and assessing the financial innovation should inform other colleagues of the supervision department (for instance those involved in onsight inspections) in order to collect more qualitative information.

iii) More in-depth analysis - if there are concrete indications for potential warnings, an in-depth assessment should start. This could require several months of qualitative and quantitative analysis (including surveys and meetings with market players). Specific on-site inspections

\footnotetext{
${ }^{66}$ The International Securities Identification Numbering (ISIN) system is an international standard set up by the International Organization for Standardization (ISO). It is used for numbering specific securities, such as stocks and bonds. ISIN numbers are administered by a National Numbering Agency (NNA) in each of the respective countries and work like serial numbers for those securities.

${ }^{67}$ For a similar initiative on the OTC derivatives, see FSB (2013a).

${ }^{68}$ The bond should be valued using the market swap curve, taking into consideration the funding cost of the issuer; the derivative component should be valued at the actual market hedging cost; alternatively it should be valued using a "standard" model.

${ }^{69}$ This probabilistic performance scenarios approach is based on three pillars. The first pillar highlights the unbundling of the price of a product at the issue date and the probability scenarios of the return of the financial investment at the end of the time horizon, providing clear and concise information on the costs of the investment and on the possible results. The second pillar is a synthetic indicator of the degree of risk of the product, i.e. a quantitative risk measure based on the volatility of the product's returns. Lastly, the third pillar is the recommended time horizon, i.e. an indication of the optimal investment holding period. For a comprehensive discussion of this approach, see Minenna (2011).
} 
could provide a valid support for both assessing potential risks and providing suggestions for policy action.

iv) Proposals for global action - on the basis of the in-depth analysis, the competent authority (for instant EBA) should decide whether to share the findings with other international bodies.

v) Performing chosen actions - after a discussion with the relevant international bodies, coordinated policy actions should be considered: interventions on specific classes of intermediaries, suggestions for enhancements of supervisory data, elaboration of a policy stance and possible legislative or normative initiatives.

\section{Box 6 - Monitoring market risks of structured products}

A - Structured product (SP) - An SP is a security with two components: a bond and a derivative component. The underlying of the derivative component cannot be the bond itself. For example, a bond with an option of repayment in advance (belonging either to the issuer or to the investor) is not an SP. The regulator should collect information on all complex structured products, defined as follow:

\section{B - Complex structured product (CSP) - A CSP has at least one of the following features:}

- $\quad$ two or more underlyings; ${ }^{70}$

- $\quad$ path dependency; ${ }^{71}$

- $\quad$ a leverage equal to or higher than 2 ;

or at least three of the following features:

- $\quad$ no listing;

- a leverage higher than 1 (but less than 2);

- no capital protection;

- $\quad$ no guaranteed coupons of at least $1 \%$ per year.

\section{Conclusions}

The net social welfare effect of financial innovation can be either positive or negative depending on several factors. On the one side, a more innovative financial system is Pareto-superior in the sense that it helps to complete the market (for instance by generating state-contingent claims for any possible future state of the world), reducing frictions and transaction costs and increasing liquidity. On the other side, it can be a source of negative externalities (generating systemic risks such as excessive leverage or volatility) and sub-optimal outcomes for some classes of economic agent (such as uninformed consumers).

Financial innovation involves consumer protection as well as systemic risk concerns. Regulation needs to be based on the identification of potential sources of threat for consumers and for the stability of markets; it is necessary to identify problems and implement solutions without curbing

\footnotetext{
70 If the underlyings are aggregated in a single index they must be considered a single underlying.

71 Path dependency means that, in order to evaluate the payoff, it is not sufficient to know the value of the underlyings at maturity of the principal or coupons, it is also necessary to know the value of the underlyings during the lifetime of the product.
} 
the stimulus to innovate. The regulator should have a strict and frank dialogue with market players, while maintaining a critical, independent and open-minded attitude.

If an innovative product has opaque or unclear returns and characteristics, transparency and disclosure could be a sufficient policy solution; if it is expected to generate not fully understood risks and consumers are affected by major behavioural biases, financial education policies should provide further support. More effective policy options (such as internal governance) can prevent the undesirable effects of certain types of financial and banking products, particularly if they are of a complex and risky nature, without being excessively intrusive. Warnings, restrictions and, in extreme cases, prohibitions are policy options that need to be carefully considered in terms of social costs and benefits, including the risk of generating regulatory arbitrages and reputational or legal costs for the regulator. The prohibition of financial innovation is a strong policy option and could create inefficiencies for the financial system.

Financial engineering, and in particular financial modelling of derivative instruments, is moving towards a more comprehensive and holistic approach, where liquidity, credit and collateral risks, as well as funding costs are considered. This is a formidable task, and several methodological problems are not fully solved yet. From a theoretical standpoint, further progress is needed not only to find proper statistical models, able to capture discontinuities, dependences structures beyond the multivariate normal distribution, and volatility clustering, but also to have a better understanding of the underling economic factors explaining such market behaviour. In the meantime, industry and regulators should work to substantially reduce risks and complexities with more robust market infrastructures and better regulation.

Finally, as we observed at the beginning of our overview on financial innovation, we avoided discussing in depth the ethical aspects of this topic, which are outside the scope of this paper and our capabilities. However, we would like to conclude with the following quotation from Amartya Sen: "Careful assessment of consequences is central to financial ethics and cannot be replaced by appeals to consequence-independent 'duties'. I have argued [...], that rules and regulations as well as codes of conduct may be serious[ly] misdirected by the attempt to base public decisions or private behaviour on the simple deontology of immediate concerns and obligations. In financial matters, no less than in other economic fields, the significant goes well beyond the proximate" (Sen, 1991, p. 64). 


\section{References}

Acharya, V. V. (2009), "A theory of systemic risk and design of prudential bank regulation", Journal of Financial Stability, 5, pp. 224-255.

Allen, F. and Gale D. (1994), Financial Innovation and Risk Sharing, The MIT Press, Cambridge Massachusetts.

Arcand, J-L, Berkes E. and Panizza U. (2012), “Too Much Finance?”, IMF Working Papers 12/161.

Armstrong, M., Cornut G., Delacòte S., Lenglet M., Millo Y., Muniesa F., Pointer A. and Taldjedine Y. (2011), "Towards a practical approach to responsible innovation in finance: New Product Committees revisited", Working group on Responsible Innovation in Finance, Observatory for Responsible Innovation, Mines Paris Tech.

Bank for International Settlements (1986), "Recent innovation in international banking”, BIS, April, Basel.

Becker, M., Döhrer B. and Johanning, L. (2012) "Considerations to Improve Investor Protection: Transparency versus Complexity of Financial Products”, Discussion paper, WHU - Otto Beisheim School of Management, May.

Bernanke, B. S. (2007), "Regulation and Financial Innovation", speech, Financial Markets Conference, Federal Reserve Bank of Atlanta, Sea Island, May 15.

BCBS (2006), Basel II: International Convergence of Capital Measurement and Capital Standards: A Revised Framework - Comprehensive Version.

BCBS (2010), Principles for enhancing corporate governance, Bank for International Settlements, October.

BIS, ECB, IMF (2009), Handbook on Securities Statistics, second draft, February.

Bhattacharyya, S. and Nanda V. (2000), "Client Discretion, Switching Costs, and Financial Innovation”, The Review of Financial Studies, vol. 13, 1101-1127.

Bikhchandani, S. and Sharma S. (2000), "Herd behaviour in financial markets: a review", IMF Working Papers 00/48.

Bianchetti, M. and Carlicchi M. (2011), "Interest Rates After the Credit Crunch - Multiple Curve Vanilla Derivatives and SABR", The Capco Journal of Financial Transformation - Applied Finance n. 32, September.

Boatright, J. R. (2010) ed., Ethic and Finance, John Willy \& Sons, Kolb Series in Finance,

Bradley, B. O. and Taqqu M. S. (2003), "Financial Risk and Heavy Tails", in S.T. Rachev (ed.) Handbook of Heavy-tailed Distributions in Finance, North Holland.

Brigo, D., Morini M. and Pallavicini A. (2013), Counterparty Credit Risk, Collateral and Funding: with Pricing Cases for All Asset Classes, Wiley \& Sons. 
Carver, L. (2012), “No more heroes in quantitative finance?”, Risk, August.

Coval, J., Jurek J. and Stafford E. (2009), "The economics of structured finance", Journal of Economic Perspectives, 23.

CRMPG III (2008), “Containing Systemic Risk: The Road to Reform”, August.

Daniel, K., Hirshleifer D. and Subrahmanyam A. (1998), "Investor Psychology and Security Market Under- and Overreactions," Journal of Finance, 53 (6).

DellaVigna, S. (2009), "Psychology and Economics: Evidence from the Field", Journal of Economic Literature, 47, June, pp. 315-372.

Donnelly, C. and Embrechts P. (2010), "The devil is in the tails: actuarial mathematics and the subprime mortgage crisis", ASTIN Bulletin 40(1), 1-33.

EBA (2011), EBA Guidelines on Internal Governance (GL 44), London, September.

ESMA (2012a), Guidelines on certain aspects of MiFID compliance function requirements, final report, ESMA/2012/388, July.

ESMA (2012b), Guidelines on certain aspects of MiFID suitability requirements, final report, ESMA/2012/387, July.

EU, Directive 2004/39/EC of the European Parliament and of the Council of 21 April 2004 on markets in financial instruments, Official Journal of the European Union, 30/04/2004.

EU, Regulation, n. 1093/2010 of the European Parliament and of the Council of 24 November 2010 establishing a European Authority (European Banking Authority), Official Journal of the European Union, 15/12/2010.

European Commission (2011), "Facts and figures on state aid in the EU Member States", Commission Staff Working Document, SEC (2011) 1487, December.

European Commission (2012a), "Legislation on legal certainty of securities holding and dispositions", Directorate General Internal Market and Services, Discussion paper, October.

European Commission (2012b), "Commission plans to modernise European company law and corporate governance", December.

FCA (2013), "Applying behavioural economics at the Financial Conduct Authority", Occasional Paper, n. 1, April.

Fama, E. F. (1998), Market efficiency, long-term returns, and behavioural finance, Journal of Financial Economics, n. 49, 283-306.

Finnerty, J. D. (1993), “An Overview of Corporate Securities Innovation”, Journal of Applied Corporate Finance (4): 23-39.

Focardi, S. and Fabozzi F. J. (2009), "Black swans and eagles: on mathematics and finance", Mathematical Methods in Operations Research, Volume 69, Number 3 (2009), 379-394. 
FSA (2008), “Consumer Responsibility”, Discussion Paper n. 8, December.

FSA (2009), “The Turner Review: A regulatory response to the global banking crisis", March.

FSA (2011), “Product Intervention”, Discussion Paper n. 11, January.

FSB (2011a), Shadow banking: Strengthening Oversight and Regulation, October.

FSB (2011b), Consumer Finance Protection with particular focus on credit, October.

FSB (2012), "Increasing the Intensity and Effectiveness of SIFI", Supervision Progress Report to the G20 Ministers and Governors, November.

FSB (2013a), “OTC Derivative Market Reform”, March.

FSB (2013b), "Principles for Effective Risk Appetite Frameworks", July.

Gennaioli, N., Shleifer A. and Vishny R. (2012), "Neglected risks, financial innovation, and financial fragility", Journal of Financial Economics, 104, pp- 452-468.

Goldman Sachs (2011), Report of the Business Standard Committee, January 2011.

Guiso, L., and Sodini P. (2012), "Household Finance: An Emerging Field". Einaudi Institute for Economics and Finance, EIEF Working paper 04/12, March.

Hall, B. (2003), "Innovation and Diffusion" in Handbook of Innovation, ed. Fagerberg, Jan, Davis Mowery, and Richard Nelson, 459-483.Oxford University Press.

Hare, R. M. (1989), Essays in Ethical Theory, Oxford University Press, Oxford.

Harsanyi, J. C. (1982), "Morality and the theory of rational behaviours", Sen, A. K. and B. Williams 1982) eds., Utilitarianism and Beyond, Cambridge University Press, Cambridge.

IOSCO (2011a), "Mitigating Systemic Risk. A Role for Securities Regulator” Discussion Paper, February.

IOSCO (2011b), "Methodology for Assessing Implementation of the IOSCO Objectives and Principles of Securities Regulation, FR08/11, September.

IOSCO (2012a), “Global Developments in Securitization Regulation: Consultation Report”, June.

IOSCO (2012b), “The Credit Default Swap Market”, FR05/12, June.

IOSCO (2013a), "Suitability Requirements with Respect to the Distribution of Complex Financial Products", FR01/13, January.

IOSCO (2013b), "Regulation of Retail Structured Products. Consultation Report”, CR05/13, April.

Kimball, M. S. (1990) "Precautionary Saving in the Small and in the Large", Econometrica, 58, 5373. 
Kimball, M. S. (1992) "Precautionary Motives for Holding Assets" in The New Palgrave Dictionary of Money and Finance, edited by Peter Newman, Murray Milgate, and John Eatwell, pp. 158-61, New York: Grove's Dictionaries Inc.

Koslowski, P. (2011), The Ethic of Banking: Conclusions from the Financial Crisis, Springer.

Kutschera von, F. (1982), Grundlagen der Ethik. Walter de Gruyter, Berlin. Fondamenti dell'Etica (eds by Antonella Corradini) - Milano, F. Angeli (1991).

Lerner, J. (2006), "The new new financial thing: the origin of financial innovations", Journal of Financial Economics, 79, 223-255.

Lerner, J. and Tufano P. (2011), "The Consequences of Financial Innovation: A Counterfactual Research Agenda", NBER Working Papers, n. 16780, February.

Liikanen E. (2012), High-level group on reforming the structure of the EU banking sector, Brussels, October.

Lo, A. W. (2005), "Reconciling efficient market with behavioural finance: the adaptive markets hypothesis", Journal of Investment Consulting, 7, 21-44.

Lo, A. W. (2007), "Efficient Markets Hypothesis", in L. Blume, S. Durlauf, The new Palgrave: a dictionary of economics, eds., 2nd Edition, Palgrave Macmillan Ltd., 2007.

Lumpkin, S. A. (2009), "Regulatory Issues Related to Financial Innovation", OECD, Financial Market Trends, vol. 2, pp. 1-31.

Lumpkin, S. A. (2010), "Consumer Protection and Financial Innovation: A Few Basic Propositions, OECD, Financial Market Trends, vol. 1, pp. 1-23.

Merton, R. C. (1995), “A functional perspective of financial intermediation”, Financial Management, 24 (2):23-41.

Merton, R. C. (2006) "Paul Samuelson and Financial Economics", American Economist, Fall, n. 50, 9-31.

Minenna, M. (2011) “A Quantitative Framework to Assess the Risk-Reward Profile of Non-Equity Products”, Risk Books.

Mirrlees, J. A. (1982), “The economic uses of utilitarianism”, in Sen, A. K. and B. Williams (1982) eds., Utilitarianism and Beyond, Cambridge University Press, Cambridge, pp- 63-84.

Neftci, S. N. (2004), Principles of Financial Engineering, Elsevier Academic Press.

Noussair C. N., Trutmann S. T. and Van de Kuilen G. (2011), "Higher order risk attitudes, demographics, and financial decisions”, Discussion Paper n. 2011-055, Tilbur University.

O’Creevy, F. M. (1999), Trading on Illusions: Unrealistic Perceptions of Control and Trading Performance, European University Institute. 
OECD (2010), Corporate Governance and the Financial Crisis. Conclusions and emerging good practices to enhance implementations of the Principles, Directorate for Financial and Enterprise Affair. 24 February.

OECD - Bank of Italy (2010), Symposium on Financial Literacy, Rome, 9 June.

OECD (2011), “High-Level Principles on Financial Consumer Protection”, October.

Piazza, R. (2010), Financial Innovation and Risk, The Role of Information, IMF Working Paper, $\mathrm{WP} / 10 / 266$.

Piterbarg, V. (2010) "Funding Beyond Discounting: Collateral Agreements and Derivative Pricing", Risk Magazine, 23, 2, 97-102.

Rachev, S. T., Kim Y. S., Bianchi M. L. and Fabozzi F. J., (2011), Financial Models with Lévy Processes and Volatility, Wiley \& Sons.

Ratnovski, L., Perotti E. C. and Vlahu R. (2011), “Capital Regulation and Tail Risk”, IMF Working Papers 11/188.

Salazar, A. R. (2011), "Libertarian Paternalism and the Danger of Nudging Consumers", King's Law Journal: King's College London Law Journal, 2012.

Schinasi, G. J. (2005), Safeguarding financial stability: theory and practice, Washington, D.C., International Monetary Fund.

Scherbina, A. (2013), “Asset Price Bubbles: A Selective Survey”, IMF Working Paper, WP/13/45.

Sen, A. K. (1991), Money and Value: On the Ethics and Economics of Finance, Banca d'Italia, Paolo Baffi Lectures on Money and Finance, Edizioni dell'Elefante.

Sen, A. K. and Williams B. (1982) eds., Utilitarianism and Beyond, Cambridge University Press, Cambridge.

Senior Supervisory Group (2009), "Risk Management Lessons from the Global Banking Crisis of 2008", October.

Sheedy, E. (2009), “Can Risk Modeling Work”, MAFC Research Papers n. 35, June, Macquarie University.

Shiller, R. J. (1999), "Human behaviour and the efficiency of financial markets", Handbook of Macroeconomics, Volume I, Edited by J. B. Taylor and M. Woodford, Chapter 20.

Stiglitz, J. E. (2009), “The Financial Crisis of 2007/2008 and its Macroeconomic Consequences”, in Stephany Griffith-Jones, J. A. Ocampo and J. E. Stiglitz (eds), Time for a Visible Hand: Lessons from the 2008 World Financial Crisis, Oxford University Press, New York, 2009.

Stoimenov, P. A. and Wilkens S. (2005), "Are structured products fairly priced? An analysis of the German market for equity-linked instruments", Journal of Banking and Finance, 29, 2971-2993.

Thaler, R. H. and Sunstein C. R. (2003), "Libertarian Paternalism”, American Economic Review, vol. 93, n.2, Papers and Proceedings. 
The Economist (2012), "Special Report on Financial Innovation” (February 25 $5^{\text {th }} 2012$ ).

Tucker, P. (2011), "Discussion of Lord Turner's Lecture", speech given at Clare Distinguished Lecture in Economics, Cambridge, Friday 18 February 2011.

Tufano, P. (2003), "Financial Innovation", Chapter 6, Handbook of Economic Finance, edited by G.M. Constantinides, M. Harris and R. Stulz, Elsevier.

Turner, A. (2012), "Securitisation, shadow banking and the value of financial innovation", The Rostov Lecture on International Affairs, SAIS, Johns Hopkins University, April.

Tversky, A. and Kahneman, D. (1991), "Loss aversion in riskless choice: a reference-dependent model”, Quarterly Journal of Economics, November, pp. 1040-61.

Visco, I. (2010). "Financial education in the aftermath of the financial crisis". OECD - Bank of Italy Symposium on Financial Literacy, "Improving financial education efficiency", Rome, 9 June.

Visco, I. (2012), "What does society expect from the financial sector?", speech, Per Jacobson Lecture by Dr Y. Reddy, June 2012, Basel.

Visco, I. (2013), “The Financial Sector After The Crisis", Imperial Business Insight, Imperial College, London, 5 March.

Walmsley, J. (1988), The New Financial Instruments: An Investor's Guide, New York: John Wiley and Sons.

World Economic Forum (2012), "Rethinking Financial Innovation: Reducing Negative Outcomes While Retaining the Benefits", World Economic Forum Reports. 


\section{Appendix}

\section{A: Economic aspects}

The efficient market hypothesis holds that market prices fully reflect all available information. It is based on the assumption that market participants act rationally and that they are able to elaborate the available information correctly; the market creates a large range of contracts that enable participants to meet their preference for risk, return and liquidity.

Problems arise when the conditions for market efficiency are not met, generating market failures, as in the case of asymmetric information, or the underlying assumptions are rejected, as in the case of the rationality assumption.

\section{Asymmetric information}

A situation in which one party to a transaction has more or better information than the other. This often happens in transactions where the seller knows more than the buyer, although the reverse can happen as well. Potentially, this could be harmful because one party can take advantage of the other's lack of knowledge; information asymmetry can generate two main problems, adverse selection and moral hazard.

\section{Misalignment of incentives}

A principal-agent problem arises when the interests of the managers of financial institutions are not aligned with those of the shareholders. The latter are interested in optimal strategies to make the company most profitable in the long run, maximizing their stock value and dividends. But a bad structure of incentives for managers, such as the bonuses attached to short-term profits that were employed before the financial crisis, may encourage managers to seek short-term profits at the expense of a very high medium- and long-term risk. ${ }^{72}$

\section{$\underline{\text { Negative externalities }}$}

The financial distress of one bank may have external effects, causing further financial distress or even the failure of other banks. This contagion effect can generate systemic risk. The central idea is that multiple failures are causally linked, and that the linkages reflect some kind of externality. ${ }^{73}$

\section{$\underline{\text { Bounded rationality - non-rational behaviour }}$}

Analysis of the behaviour of market participants has shown that in some cases individuals may not act rationally; when this happens, an assumption of the efficient market hypothesis is not valid, and market outcomes are inefficient. Behavioural finance is the study of the influence of psychology on the behaviour of financial practitioners and the subsequent effect on markets. Behavioural finance is of interest because it helps to explain why and how markets might be inefficient; various studies in this field have documented different forms of cognitive bias, ${ }^{74}$ such as overconfidence, overreaction, herding behaviour, miscalibration of probabilities.

Overconfidence is the excessive trust individuals place in their own judgement; it causes underreaction to new external information, excessive trust in the ability to control events, and underestimation of risks, a phenomenon recognized by psychologists and known as illusion of control. $^{75}$

\footnotetext{
${ }^{72}$ Stiglitz (2009).

${ }^{73}$ See, for instance, V.V. Acharya (2009). See also Schinasi (2006).

${ }^{74}$ Lo (2007).

${ }^{75}$ O’Creevy (1999).
} 
According to the market efficiency hypothesis, new information should be reflected more or less instantly in a security's price. If economic agents underreact, the new information, rather than being immediately reflected in the price, is priced more gradually; in case of overreaction to new information, prices adjust too far and then drift back. ${ }^{76}$

Herding behaviour by market participants increases the volatility of prices, destabilizes markets and increases the fragility of the financial system. Individuals are said to herd when they do not make an investment they would otherwise have made because other investors have decided not to do so, or similarly make an investment they would not have made because others have done so. ${ }^{77}$

\section{Regulatory failures}

Regulatory failures refer to the possibility of regulation itself yielding sub-optimal outcomes. This can happen when regulations create regulatory gaps, between both different entities and different jurisdictions, thus generating an unlevel playing field and incentives for regulatory arbitrage. Excessive regulation may also curb the incentive to innovate.

\section{$\underline{\text { Regulatory gaps }}$}

Inconsistency between different aspects of financial regulation can lead to regulatory arbitrage by banks seeking yields. Until the recent crisis, differences between prudential and accounting regulations prompted banks to move assets towards Special Purpose Vehicles or Conduits, favouring the development of innovative credit risk transfer products and the growth of the shadow banking system, which consists of financial entities or activities generating bank-like risks across the global financial system that are not subject, in most jurisdictions, to fully-fledged prudential regulation. Such entities or activities used to finance themselves by borrowing liquidity or issuing short-term liabilities and investing in long-term assets such as structured securities. As a result, many of them faced high market and liquidity risks. They bore the credit risk related to loans underlying CRT (Credit Risk Transfer) instruments but did not have sufficient capital to back this and other types of risk. Several forms of CRT were mispriced. Furthermore, unlike banks, they did not have access to central banks' lender of last resort liquidity. These aspects were an important source of systemic risk.

Inconsistency in prudential regulation between jurisdictions can produce an unlevel playing field for banks and prompt those benefiting from less stringent supervision to take on increasing risks; interconnections between banks can spread the risks throughout the financial system. The light touch supervision adopted in some jurisdictions is an example. It was based on the assumption that the market self-regulates, the primary responsibility for managing risks lies with the senior management and boards of the individual firms, and customer protection is best ensured not by product regulation or direct intervention in markets, but by ensuring that wholesale and retail markets are transparent.

At the same time, after the financial crisis it became clear that innovative forms of financial intermediation were unregulated or subject to less stringent rules than banks. Specialized lenders, mutual and hedge funds, and investment banks are some of the intermediaries that were subject to a different regulation from banks even if they indirectly participated with banks in the process of providing loans via the purchase of innovative CRT products.

\section{Inconsistency of regulations with respect to the same kind of risk}

As we have seen, most non-banks used to bear liquidity, market and credit risks like banks as they were among the main purchasers of innovative financial CRT products and financed themselves in

\footnotetext{
${ }^{76}$ Daniel et al. (1998).

${ }^{77}$ Bikhchandani and Sharma (2000).
} 
short-term liquidity markets. Nevertheless, they were not subject to the same prudential rules as banks regarding liquidity, market and credit risk. Furthermore, unlike banks, they did not have access to central banks' lender of last resort liquidity.

\section{Incentives for financial innovation}

As we have seen, incentives for financial innovation prior to the crisis had a number of shortcomings: the short-term incentive-pay based system for managers and the possibility to move assets towards vehicles by securitization may have played a role both in the huge increase observed in CRT products and in the deterioration of the credit underlying standards until the crisis. Nevertheless, the complex system of new rules under construction and the new supervision powers of authorities now being designed should not curb the incentives for banks to seek innovative products and begin once again to make recourse to securitization as an important source of funding. 


\begin{tabular}{|c|c|c|}
\hline & & Table 2 \\
\hline \multicolumn{3}{|c|}{ Financial innovation $\&$ risks } \\
\hline & Problem & Policy option \\
\hline $\begin{array}{l}\text { Incomplete } \\
\text { information }\end{array}$ & $\begin{array}{l}\text { When consumers are not provided with complete information, they may } \\
\text { buy products that do not meet their preferences for risk, return or } \\
\text { liquidity. This can create reputational and legal risks for the banks. }\end{array}$ & \multirow{3}{*}{$\begin{array}{l}\text { - Promote transparency; } \\
\text { - Promote consumer awareness; } \\
\text { - Consumer education, promote } \\
\text { user friendly products; } \\
\text { - Warning or technical standards; } \\
\text { - New Product Committee. }\end{array}$} \\
\hline $\begin{array}{l}\text { Bounded } \\
\text { rationality: } \\
\text { complexity } \\
\text { (demand side) }\end{array}$ & $\begin{array}{l}\text { Overly complex products may not be fully understood by consumers, } \\
\text { even when provided with full information; consumers may buy products } \\
\text { that do not meet their preferences for risk, return or liquidity. This can } \\
\text { create reputational and legal risks for the banks. }\end{array}$ & \\
\hline $\begin{array}{l}\text { Bounded } \\
\text { rationality: } \\
\text { irrational behaviour }\end{array}$ & $\begin{array}{l}\text { Consumers may not use information in a rational way, but instead their } \\
\text { behaviour is subject to overreaction, overconfidence, herding effects }\end{array}$ & \\
\hline $\begin{array}{l}\text { Over-complexity } \\
\text { (supply side) }\end{array}$ & $\begin{array}{l}\text { Improper use of financial models and over-reliance on inadequate } \\
\text { mathematical models cause mispricing of products and incorrect } \\
\text { evaluation of risks. }\end{array}$ & $\begin{array}{l}\text { - On-site inspections; } \\
\text { - Full disclosure of assumptions; } \\
\text { - Better corporate governance } \\
\text { - New Product Committee. }\end{array}$ \\
\hline $\begin{array}{l}\text { Serious (systemic) } \\
\text { negative } \\
\text { externalities }\end{array}$ & $\begin{array}{l}\text { The failure of one or more financial institutions can cause instability in } \\
\text { the whole market through the large net of interconnections between the } \\
\text { various banks. From an economic point of view, systemic risk can be } \\
\text { seen as a negative externality. }\end{array}$ & $\begin{array}{l}\text { - Remove the factors that drive } \\
\text { mechanisms of contagion and } \\
\text { pro-cyclicality; } \\
\text { - Technical standards; } \\
\text { - Product restrictions or bans. }\end{array}$ \\
\hline $\begin{array}{l}\text { Moral hazard, } \\
\text { Misalignment } \\
\text { of incentives } \\
\text { (Principal-Agent } \\
\text { problem) }\end{array}$ & $\begin{array}{l}\text { Bonuses for managers based on short-term profits leads to excessive risk } \\
\text { taking. } \\
\text { Most traders have a bonus or incentive element in their remuneration that } \\
\text { includes an option-like feature: they share in the profits they make but } \\
\text { not in the losses. To maximize their expected remuneration, therefore, } \\
\text { they take on as much risk as possible. } \\
\text { At management level, there may be inadequate incentives for an } \\
\text { individual to diagnose and draw attention to problems, and to implement } \\
\text { solutions to them. }\end{array}$ & $\begin{array}{l}\text { - Better corporate governance; } \\
\text { - Better remuneration policy; } \\
\text { - New Product Committee. }\end{array}$ \\
\hline $\begin{array}{l}\text { Regulatory } \\
\text { arbitrage }\end{array}$ & $\begin{array}{l}\text { Inconsistency between different aspects of financial regulation can lead } \\
\text { to regulatory arbitrage by banks seeking yields. } \\
\text { Innovative credit risk transfer products can be used by banks to transfer } \\
\text { risk to a wide part of the financial intermediation system that is } \\
\text { unregulated or subject to less stringent rules than banks. }\end{array}$ & $\begin{array}{l}\text { - Oversight on-site inspections, } \\
\text { prudential regulation on } \\
\text { intermediaries (including shadow } \\
\text { entities); } \\
\text { - Monitoring; }\end{array}$ \\
\hline $\begin{array}{l}\text { Incentives for } \\
\text { financial innovation }\end{array}$ & $\begin{array}{l}\text { Regulation should not curb the incentives for banks to look for } \\
\text { innovative products. }\end{array}$ & $\begin{array}{l}\text { - Frank dialogue between } \\
\text { regulators and market players. }\end{array}$ \\
\hline
\end{tabular}




\section{B: Recent developments in consumer protection ${ }^{78}$}

The European Commission has developed a large number of policy initiatives focusing on retail banking products and services, involving the analysis of market practices, public hearings and consultations, and a proposal for new regulations and directives, some of which are currently under discussion. Special attention has been paid to the credit market and to issues such as responsible lending and borrowing, ${ }^{79}$ leading to the approval of a new Consumer Credit Directive in $2008^{80}$ and to the proposal for a Mortgage Credit Directive in 2011. ${ }^{81}$ The European Commission has also been working on other issues of interest to retail banking, such as Packaged Retail Investment Products (PRIPs), ${ }^{82}$ tying of banking products, ${ }^{83}$ bank account fees transparency and switching, ${ }^{84}$ electronic payments, financial inclusion ${ }^{85}$ and practices of responsible lending to SMEs. ${ }^{86}$

In February 2011, the G20 called on the OECD, the Financial Stability Board (FSB) and other international organizations to develop common principles on consumer protection in the field of financial services. At their meeting in October 2011, G20 Finance Ministers and Central Bank Governors endorsed the High-level Principles on Financial Consumer Protection ${ }^{87}$ developed by an OECD-led Task Force on Financial Consumer Protection. These high-level principles were designed to assist efforts to enhance financial consumer protection, and to complement existing international financial principles or guidelines. They cover ten key areas: legal, regulatory and supervisory framework; the role of oversight bodies; the equitable and fair treatment of consumers; disclosure and transparency; financial education and awareness; responsible business conduct of financial services providers and authorized agents; the protection of consumer assets against fraud and misuse; the protection of consumer data and privacy; complaints handling and redress; and competition.

Following the meeting of the G20 in February 2012, which stated that work should be advanced as regards the financial consumer protection agenda, an Action Plan on Effective Practices to Support the Implementation of the High-Level Principles on Financial Consumer Protection ${ }^{88}$ was presented by the G20/OECD Task Force on Financial Consumer Protection and endorsed by the G20 Finance Ministers and Central Bank Governors in June 2012. In July 2012 the OECD Council adopted the High-Level Principles as a recommendation. Due to the fact that a large number of jurisdictions stated they would like additional information to support their efforts towards the implementation of the principles, the objective of the plan is to identify, within 24 months, a set of effective approaches to support that implementation, focusing on the three following priority principles: (i) Disclosure and Transparency (principle 4), (ii) Responsible Business Conduct of Financial Services Providers and Authorised Agents (principle 6) and (iii) Complaints Handling and Redress (principle 9). Furthermore, work to support the implementation of the principle on the role of oversight bodies will be delegated to the Standard Setting Bodies. Work to support the implementation of the

\footnotetext{
${ }^{78}$ This section is based on "Task Force on Intervention Strategy", Standing Committee on Consumer Protection and Financial Innovation, EBA, mimeo, December 2012, Annex 1 (by Maria Lucia Leitao).

${ }^{79} \mathrm{http}: / /$ ec.europa.eu/internal_market/finservices-retail/credit/responsible_lending_en.htm

${ }^{80}$ Directive 2008/48/EC of the European Parliament and of the Council of 23 April 2008 on credit agreements for consumers.

${ }^{81}$ Proposal for a Directive of the European Parliament and of the Council on credit agreements relating to residential property $(\mathrm{COM} / 2011 / 0142)$.

${ }^{82} \mathrm{http}: / /$ ec.europa.eu/internal_market/finservices-retail/investment_products_en.htm

${ }^{83} \mathrm{http}: / /$ ec.europa.eu/internal_market/finservices-retail/mobility/tying_en.htm

${ }^{84} \mathrm{http}: / /$ ec.europa.eu/internal_market/finservices-retail/mobility/bank_switching_en.htm

${ }^{85} \mathrm{http}: / /$ ec.europa.eu/internal_market/finservices-retail/inclusion_en.htm

${ }^{86} \mathrm{http}: / /$ ec.europa.eu/enterprise/policies/finance/files/com-2011-8̄870_en.pdf

${ }^{87} \mathrm{http}: / / w w w . o e c d . o r g /$ dataoecd/58/26/48892010.pdf

${ }^{88} \mathrm{http} / / /$ www.g20.org/images/stories/canalfinan/deliverables/financial_inclusion/G20_draft_action_plan.pdf
} 
principle on financial education will be conducted directly by the OECD International Network for Financial Education (INFE).

The International Network on Financial Education (INFE), fostered by the OECD and composed of financial regulators, public authorities and experts, has done extensive work on the definition and disclosure of guidelines on the promotion of financial education as well as on the development of the High-Level Principles for the Evaluation of Financial Education Programmes on National Strategies of Financial Education. ${ }^{89}$ The G20 Leaders have recently endorsed the OECD/INFE High-Level Principles on National Strategies for Financial Education and have called for further tools to promote financial education.

\section{C: Correlations and dependency structures}

Correlation is the traditional measure of dependence between random variables, but it explains only linear dependence and moreover it is not invariant under non-linear strictly increasing transformations. A more general dependency structure is the joint distribution of probabilities; given the marginal distributions of the random variables, it can be constructed by means of a copula function that specifies a dependency structure between them. The use of copulas offers some advantages: the nature of the dependency that can be modelled is very general, whereas correlation explains only linear dependence; copulas are indifferent to continuously increasing transformations; dependence of extreme events might be modelled.

The knowledge of the marginal distribution function, together with a scalar parameter of dependency, does not uniquely determine the joint density function of two random variables; different choices for the copula function will determine different joint distributions for the random variables. Among the various possibilities, the Gaussian copula has been preferred and widely used for its simplicity; as it is based on the assumption that all the random variables have pairwise the same correlation, it only requires this correlation to be estimated in order to compute the joint distribution. However, as highlighted by Donnelly and Embrechts (2010), ${ }^{90}$ this simple structure has various drawbacks; for example, when used to price CDOs, it does not model properly the default clustering in the underlying portfolio: in times of crisis, corporate defaults occur in clusters, so that if one company defaults then it is likely that other companies will also default; the Gaussian copula model is not appropriate in this contest as it assigns very low probabilities to the joint default of companies. More in general, when we are interested in modelling the joint occurrence of extreme events, the choice we make for the copula is critically important; the assumption of the Gaussian copula, while convenient for its simplicity, implies that joint extreme events are much less likely to occur than under other copulas.

To clarify this point better, it should be recalled that the copula function, specifying the dependency structure of random variables, provides a bridge between the univariate distribution of the individual random variables and their joint distribution; given the marginal distributions, we can obtain all possible joint distributions by varying the copula function. Among the possible copulas, some are more appropriate to model tail dependence, that is dependence between extreme events, possibly present in financial data; these copulas (e.g. the Gumbel copula) specify a dependence structure in which, if a variable takes an extreme value, the probability of other random variables taking extreme values is high. The Gaussian copula (widely used by market players and rating agencies because more rapid and easy to compute) does not have tail dependence, so it assigns very low probabilities to events in which all random variables take extreme values.

\footnotetext{
${ }^{89} \mathrm{http}: / /$ www.oecd.org/dataoecd/38/63/49373959.pdf

${ }^{90}$ Donnelly and Embrechts (2010).
} 
Figure 2 illustrates how the choice of a copula can affect the joint distribution. Each figure shows contours of constant density of a bivariate distribution $(\mathrm{X}, \mathrm{Y})$ with standard normal marginals and linear correlations $\rho \approx 0.7$. The differences in the distributions are due to the choice of copula; the Gumbel copula shows higher upper tail dependence, while the Clayton models lower tail dependence.

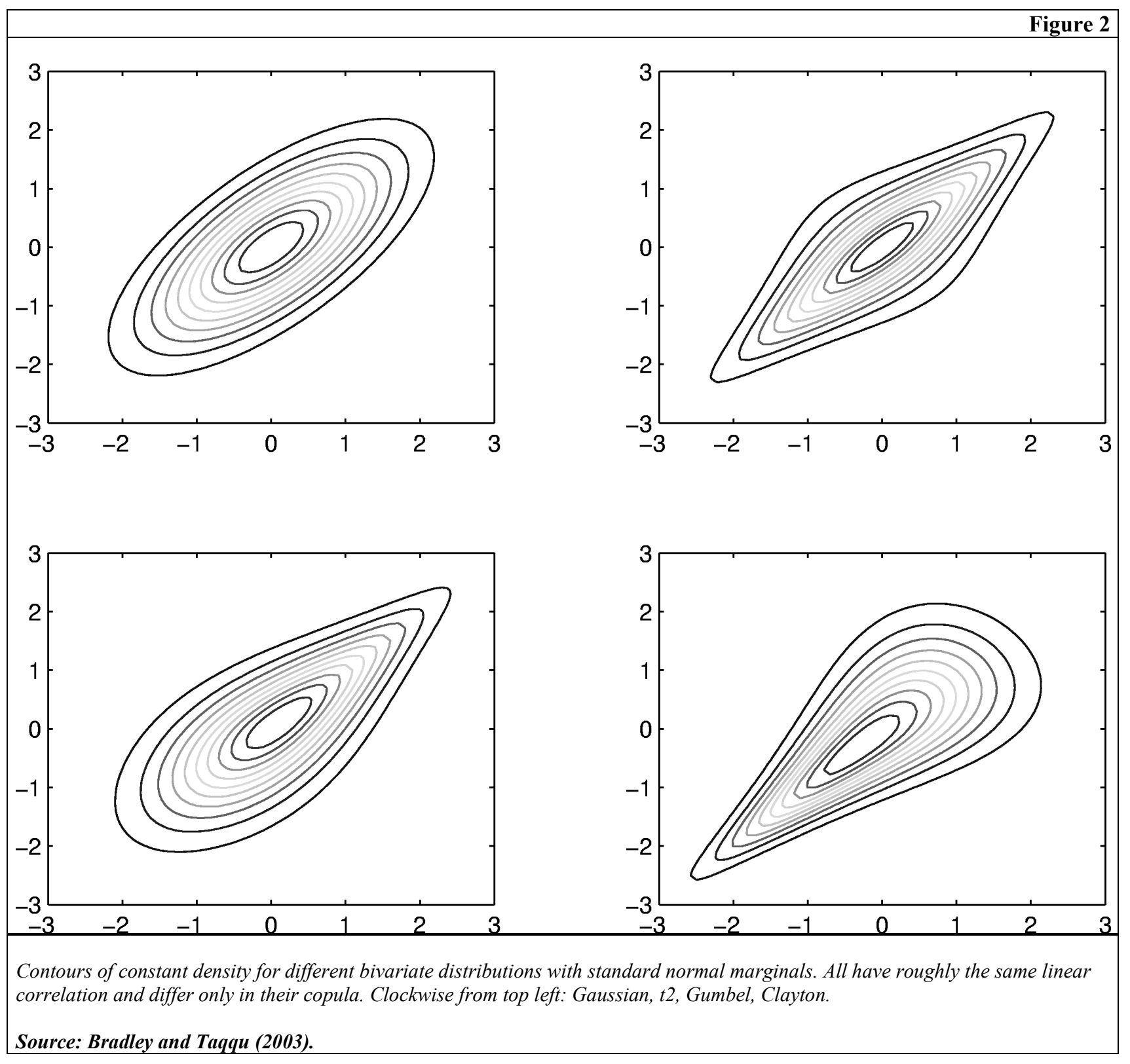




\section{D: The EBA's Guidelines on Internal Governance ${ }^{91}$}

The organization structure should follow the traditional three-lines-of-defence model. In particular, the institution should have in place 1) a risk management process to identify, measure or asses, mitigate and report on risks; 2) an internal control framework to develop and maintain systems that ensure adequate control of risks, prudent conduct business, reliable reporting and disclosure, compliance with laws, regulations and supervisory requirements; and iii) the internal audit, which independently tests the effectiveness of the processes or risk monitoring, mitigation and internal reporting. The Chief Risk Officer (CRO should be independent from revenue-generating functions and have a direct line of responsibility to the Chief Executive Officer (CEO) and the Board of Directors. The Board, which in some jurisdictions has a two-tier structure (where the supervisory function is separate from the executive function), is responsible for ensuring that the firm has an appropriate risk governance framework. It approves and oversees the risk strategy (or risk appetite framework), and sets risk limits for business units and the risk management framework. Incentives and compensation practices should be part of this process. Large institutions should consider setting up a Risk Committee composed only of independent directors.

Risk management framework: the decision process determining the level of risks taken should not only be based on quantitative information or model outputs, it should also take into account the practical and conceptual limitations of metrics and models using a qualitative approach (including expert judgement and critical analysis). Relevant macroeconomic trends and data should be explicitly addressed to identify their potential impact on exposures and portfolios. Such assessments should be formally integrated into material risk decisions. (Title III, Section 22 (6), p. 35).

An institution must have in place a well-documented New product approval policy (NPAP), approved by the management body, which addresses the development of new markets, products and services and significant changes to existing ones (Section 23 (1)). The NPAP should set out the main issues to be addressed before a decision is made. These should include regulatory compliance, pricing models, impacts on risk profile, capital adequacy and profitability, availability of adequate front, back and middle office resources and adequate internal tools and expertise to understand and monitor the associated risks. The decision to launch a new activity should clearly state the business unit and individuals responsible for it. A new activity should not be undertaken until adequate resources to understand and manage the associated risks are available (Title III, Section 23 (3)).

Internal control: The control functions should include a Risk Control Function (RCF), a Compliance function and an Internal Audit function. The control function is organizationally separate from the activities it is assigned to monitor and control (Title III, Section 24 (6b));

The control functions should be established at an adequate hierarchical level and report directly to the management body. They should be independent of the business and support units they monitor and control as well as organizationally independent from each other (since they perform different functions). However, in less complex or smaller institutions, the tasks of the Risk Control and Compliance function may be combined (Title III, Section 24 (5)).

The internal control framework should cover the whole organization, including the activities of all business, support and control units (Title III, Section 24 (2))

The Risk control function should check that each key risk the institution faces is identified and properly managed by the relevant units in the institution, and that a holistic view of all relevant risks is submitted to the management body. It should provide independent information, analyses and

\footnotetext{
${ }^{91}$ This section is based on the EBA's Guidelines on Internal Governance, September 2011
} 
expert judgement on risk exposures, and advice on proposals and risk decisions made by the management body and business or support units as to whether they are consistent with the institution's risk tolerance/appetite. The RCF may recommend improvements to the risk management framework and options to remedy breaches of risk policies, procedures and limits (Title III, Section 25 (2)).

The RCF should be an institution's central organizational feature, structured in such a way that it can implement risk policies and control the risk management framework. Large, complex and sophisticated institutions may consider establishing dedicated RCFs for each material business line. However, the institution should have a central RCF (including, where appropriate, a Group RCF in the parent company) to deliver a holistic view of all the risks (Title III, Section 25 (3)).

Finally, the Compliance function should ensure that the compliance policy is observed and report to the management body and as appropriate to the RCF on the institution's management of compliance risk. The findings of the Compliance function should be taken into account by the management body and the RCF during the decision-making process (Title III, Section 28 (4)). Moreover, the Compliance function should also verify that new products and new procedures comply with the current legal environment and any known forthcoming changes to legislation, regulations and supervisory requirements. (Title III, Section 28 (6)). 